\title{
Atmospheric inversion of surface carbon flux with consideration of the spatial distribution of US crop production and consumption
}

\author{
J. M. Chen ${ }^{1,2}$, J. W. Fung ${ }^{2}$, G. Mo ${ }^{2}$, F. Deng ${ }^{3}$, and T. O. West ${ }^{4}$ \\ ${ }^{1}$ International Institute of Earth System Science, Nanjing University, Nanjing, Jiangsu, China \\ ${ }^{2}$ Department of Geography and Program in Planning, University of Toronto, Toronto, Ontario, M5S 3G3, Canada \\ ${ }^{3}$ Department of Physics, University of Toronto, Toronto, Ontario, M5S 3G3, Canada \\ ${ }^{4}$ Joint Global Change Research Institute, Pacific Northwest National Laboratory, College Park, Maryland, USA
}

Correspondence to: J. M. Chen, (chenj@geog.utoronto.ca)

Received: 26 November 2013 - Published in Biogeosciences Discuss.: 29 April 2014

Revised: 15 September 2014 - Accepted: 3 December 2014 - Published: 19 January 2015

\begin{abstract}
In order to improve quantification of the spatial distribution of carbon sinks and sources in the conterminous US, we conduct a nested global atmospheric inversion with detailed spatial information on crop production and consumption. County-level cropland net primary productivity, harvested biomass, soil carbon change, and human and livestock consumption data over the conterminous US are used for this purpose. Time-dependent Bayesian synthesis inversions are conducted based on $\mathrm{CO}_{2}$ observations at 210 stations to infer $\mathrm{CO}_{2}$ fluxes globally at monthly time steps with a nested focus on 30 regions in North America. Prior land surface carbon fluxes are first generated using a biospheric model, and the inversions are constrained using prior fluxes with and without adjustments for crop production and consumption over the 2002-2007 period. After these adjustments, the inverted regional carbon sink in the US Midwest increases from $0.25 \pm 0.03$ to $0.42 \pm 0.13 \mathrm{Pg} \mathrm{C} \mathrm{yr}^{-1}$, whereas the large sink in the US southeast forest region is weakened from $0.41 \pm 0.12$ to $0.29 \pm 0.12 \mathrm{Pg} \mathrm{C} \mathrm{yr}^{-1}$. These adjustments also reduce the inverted sink in the west region from $0.066 \pm 0.04$ to $0.040 \pm 0.02 \mathrm{Pg} \mathrm{Cyr}^{-1}$ because of high crop consumption and respiration by humans and livestock. The general pattern of sink increases in crop production areas and sink decreases (or source increases) in crop consumption areas highlights the importance of considering the lateral carbon transfer in crop products in atmospheric inverse modeling, which provides a reliable atmospheric perspective of the overall carbon balance at the continental scale but is unreliable for separating fluxes from different ecosystems.
\end{abstract}

\section{Introduction}

Human activities have greatly modified the global carbon cycle through fossil fuel consumption, cement production, and land use (Canadell et al., 2007; Le Quéré et al., 2013). The airborne fraction of these carbon sources has been highly variable from year to year, mostly due to large variations in the terrestrial carbon sink (Le Quéré et al., 2009, 2013). Due to the complexity and heterogeneity of land cover, it has been a challenge to estimate the spatial distribution and magnitude of terrestrial carbon sources and sinks. It has been more reliable thus far to derive the terrestrial sink as a residual of the global carbon budget than to estimate it using land-based data (Le Quéré et al., 2013). Our ability to project the carbon cycle and estimate its influence on climate will remain limited if we cannot resolve the current carbon source and sink distribution patterns and provide plausible mechanistic explanations for the patterns. In this regard, regional studies that focus on the spatial distribution of carbon dynamics would be a useful direction for improving our understanding of the global carbon cycle.

With regard to regional carbon cycles, North America may be one of the most closely observed and studied regions in the world. However, the magnitude and the spatial distribution of carbon sinks and sources over the continent are still highly uncertain (Huntzinger et al., 2012; Hayes et al., 2012). In terms of the sink magnitude, atmospheric inversion studies (referred to as "top-down") performed for different time periods from 1992 to 2007 suggest that North America has been a sink ranging from 0.54 to $1.06 \mathrm{Pg} \mathrm{Cyr}^{-1}$ (Gurney et 
al., 2002, 2003, 2004; Rödenbeck et al., 2003; Baker et al., 2006; Peters et al., 2007; Deng et al., 2013; Peylin et al., 2013), while 19 biospheric models (referred to as "bottomup") produced an average sink of $0.6 \mathrm{Pg} \mathrm{C} \mathrm{yr}^{-1}$, with a range from -0.7 to $2.2 \mathrm{Pg} \mathrm{Cyr}^{-1}$, for North America over the period from 2000 to 2005 (Huntzinger et al., 2012). Using a biospheric model, Turner et al. (2013) estimated that the net ecosystem productivity (NEP) over North America in 2004 was $1.73 \pm 0.37 \mathrm{PgC} \mathrm{yr}^{-1}$, and this NEP value is reduced by $0.616 \mathrm{Pg} \mathrm{C} \mathrm{yr}^{-1}$ for the carbon loss due to harvested product emission, river/stream evasion, and fire emission in order to estimate the total land sink. These top-down and bottomup estimates at the continental scale broadly agree, giving us confidence that North America is a large and important contributor to the global terrestrial carbon sink.

With respect to the spatial distribution of the North American carbon sink, results become more uncertain at higher spatial resolutions. Disaggregation of the sink between North American boreal and temperate regions is plagued with uncertainties. For the boreal region, an inversion study (Fan, 1998) produced a sink of $0.2 \pm 0.4 \mathrm{Pg} \mathrm{C} \mathrm{yr}^{-1}$ in $1988-1992$, while a TransCom 3 experiment (Gurney et al., 2003) showed a source of $0.26 \pm 0.39 \mathrm{Pg} \mathrm{Cyr}^{-1}$ in $1992-1996$. When the TransCom 3 experiment was repeated with updated data, it became a sink of $0.003 \pm 0.28 \mathrm{Pg} \mathrm{Cyr}^{-1}$ in $1992-1996$ (Yuen et al., 2005). Using forest inventory data, Canadian forests were found to be a carbon source of $0.069 \mathrm{Pg} \mathrm{C} \mathrm{yr}^{-1}$ in 1985-1989 (Kurz and Apps, 1999), while (Pan et al., 2011a) estimated that forests in Canada and Alaska were a carbon sink of $0.26 \pm 0.06 \mathrm{Pg} \mathrm{C} \mathrm{yr}^{-1}$ in $1990-2008$. A biospheric model calculated a weak sink of $0.05 \mathrm{PgC} \mathrm{yr}^{-1}$ for Canadian forests during the 1980s to 1990s (Chen et al., 2003). For the conterminous US, with approximately $32 \%$ of the total North America area, estimates of the sink from a set of bottom-up and top-down methods fall in a range from 0.30 to $0.58 \mathrm{Pg} \mathrm{Cyr}^{-1}$ in 1980-1989 (Pacala et al., 2001), while TransCom 3 experiments inferred the sink in 19921996 to be $0.89 \pm 0.22$ and $0.82 \pm 0.40 \mathrm{Pg} \mathrm{Cyr}^{-1}$ for inversions at monthly and annual time steps, respectively (Gurney et al., 2003, 2004; Baker et al., 2006). These differences suggest that uncertainty due to the temporal resolution of inverse modeling is considerable. Peters et al. (2007) developed a carbon assimilation system implemented at weekly time steps, referred to as CarbonTracker (CT), and showed that the sink in 2000-2005 in temperate North America was $0.50 \pm 0.60 \mathrm{PgC} \mathrm{yr}^{-1}$. With a simple atmospheric budgeting approach applied to $\mathrm{CO}_{2}$ measurements in the inflows and outflows through the troposphere over the conterminous US, Crevoisier et al. (2010) deduced a sink of $0.5 \pm 0.4 \mathrm{PgC} \mathrm{yr}^{-1}$ in 2004-2006. Seven other inversion studies, on average, indicate that temperate North America was a sink of $0.685 \pm 0.574 \mathrm{PgC}^{-1}$ in 2000-2006 (see summary in Hayes et al., 2012). Although these estimates have large uncertainties, they generally indicate that the ma- jor sink in North America is located in the temperate region while the boreal region is either a small sink or source.

The locations of carbon sinks and sources within temperate North America are highly uncertain. The 19 biospheric models employed by Huntzinger et al. (2012) generated very different sink and source spatial patterns over the conterminous US, although the average sink mostly appears in forested areas in southeast, northeast and northwest regions. Another bottom-up estimate using long-term modeling and recent remote sensing inputs suggested that forests in the southeast region are large sinks because of their predominant mid-age structure (Zhang et al., 2012). Based on forest inventory data, Williams et al. (2012) deduced that forests along the east and west coasts of the US were large sinks in 2005-2006, with most areas in the southeast region (i.e., Arkansas, Louisiana, Mississippi, and Alabama) having sinks in the range of $110-140 \mathrm{~g} \mathrm{C} \mathrm{m}^{-2} \mathrm{yr}^{-1}$. However, CarbonTracker (Peters et al., 2007) repeatedly produces large sinks in cropland and adjacent grassland areas, while the southeast region varied between being a small source and a small sink. Inversion studies that divide North America into 30 regions (11 in the conterminous USA; Deng et al., 2007; Deng and Chen, 2011) indicate broad patterns of the sink distribution in both the southeast forest and Midwestern crop regions. In these two studies, the seasonal variations of the carbon flux from various terrestrial ecosystems modeled by a biospheric model and neutralized at the annual time step were used as the prior flux to constrain the inversion. Under the neutralized flux constraint, the inverted sink may be more or less regarded as the atmospheric signal, although the inversion results are inevitably influenced by errors in transport modeling and other prior fluxes such as fossil fuel, biomass burning, and ocean-atmospheric exchange. Inversion studies by Peters et al. (2007), Deng and Chen (2011), Lauvaux et al. (2012), and Schuh et al. (2013) indicate that the midwest croplands persistently behave as a large regional sink, but this sink generally does not accumulate locally in soil and vegetation due to lateral transfer of agricultural products and therefore could not be estimated from the local carbon stock changes. From the atmospheric perspective, crop production during the growing season results in large uptake of $\mathrm{CO}_{2}$ from the atmosphere, while crop consumption after harvest takes place in areas outside of croplands. Gourdji et al. (2012) found a large discrepancy between inverse and biospheric model results over crop production and consumption areas in both growing and dormant seasons and attributed this discrepancy to the lack of lateral transfer of agricultural carbon included in biospheric models, although poor biospheric model performance for crops (Huntzinger et al., 2012) could also be a reason for the discrepancy. Similarly, lateral transfer of carbon also occurs with forest products (Hayes et al., 2012). Hayes et al. (2012) successfully reconciled a large portion of this discrepancy using crop and forest product information for North America. Based on this study, it can be inferred that these lateral transports of carbon 
Table 1. Summary of background prior fluxes and their uncertainties.

\begin{tabular}{|c|c|c|c|}
\hline Background flux & Data source & Temporal variability & Uncertainty \\
\hline Fossil fuel & $\begin{array}{l}\text { CDIAC (Marland et al., 2009) + } \\
\text { EDGAR } 4 \text { database } \\
\text { (Olivier and Aardenne, 2005) }\end{array}$ & Interannual & $\mathrm{n} / \mathrm{a}$ \\
\hline Fire & GFEDv2 (Randerson et al., 2007) & Interannual & $\mathrm{n} / \mathrm{a}$ \\
\hline Biosphere & $\begin{array}{l}\text { BEPS model (Chen et al., 2012; } \\
\text { Ju et al., 2006) }\end{array}$ & $\begin{array}{l}\text { Interannual, seasonal, } \\
\text { diurnal }\end{array}$ & $\begin{array}{l}2.0 \mathrm{PgC} \mathrm{yr}^{-1} \text { (Gurney et al., 2003) } \\
\text { distributed globally over } \\
\text { land surfaces regions based } \\
\text { on spatial pattern of the GPP }\end{array}$ \\
\hline Ocean & $\begin{array}{l}\text { OPA-PISCES-T model } \\
\text { (Buitenhuis et al., 2006) }\end{array}$ & Seasonal & $\begin{array}{l}0.67 \mathrm{PgC} \mathrm{yr}^{-1} \text { distributed over } \\
\text { ocean regions (Deng and Chen, 2011) }\end{array}$ \\
\hline
\end{tabular}

need to be considered in both bottom-up and top-down modeling in order for them to converge on similar spatial patterns of the carbon sink and source distribution.

The necessity of including lateral transfer of carbon in the prior flux for constraining inverse modeling can be questioned because it could be argued that atmospheric $\mathrm{CO}_{2}$ measurements have already integrated the outcome of all carbon cycle processes including the lateral movement of carbon both at the surface and in the atmosphere. Theoretically, this argument is well grounded if we have sufficient atmospheric $\mathrm{CO}_{2}$ measurements, and it could possibly hold true for North America, which is one of the most densely observed regions in the world with respect to atmospheric $\mathrm{CO}_{2}$. However, the extent to which the carbon source and sink distribution over North America is determined by atmospheric $\mathrm{CO}_{2}$ measurements has not been systematically assessed. The Bayesian synthesis inversion framework, in which a prior flux is used to constrain the inversion (Enting, 2002), provides an ideal tool for this assessment. The extent to which the inverted flux distribution is influenced by the inclusion of lateral carbon transfer in the prior flux could be an indicator of the strength of existing atmospheric $\mathrm{CO}_{2}$ measurements on the carbon cycle relative to the prior flux.

In this study, we attempt first to include crop production and consumption information in the prior flux for constraining our existing inverse modeling system (Deng and Chen, 2011) and then to assess the necessity of this inclusion for determining the carbon source and sink distribution over North America. The consumption of crop products by livestock and humans is about twice the consumption of forest products (West et al., 2011; Hayes et al., 2012). Unlike forest products with a large range of residence times, crop products can be assumed to be consumed within a year of harvest (West et al., 2011). The spatial distributions of crop production and consumption at the county level (West et al., 2011) provide a sufficient resolution for use in atmospheric inverse modeling. The specific objectives of our study are: (1) to investigate the changes in the inverted carbon source and sink distribution after considering the spatial patterns of crop production and consumption, (2) to explore whether these changes improve our understanding of the carbon source and sink distribution within the conterminous US, (3) to evaluate the impact of the crop data on the inverted carbon balance for the conterminous US and other regions of the globe, and (4) to assess the relative importance of atmospheric $\mathrm{CO}_{2}$ data and the prior flux in determining the spatial pattern of the carbon sink in the conterminous US.

\section{Atmospheric $\mathrm{CO}_{2}$ inversion methodology}

The Bayesian synthesis inversion method (Enting and Trudinger, 1995) is used in this study. This method includes forward modeling of atmospheric $\mathrm{CO}_{2}$ concentration using a transport model with prior fluxes and inverse modeling of the surface $\mathrm{CO}_{2}$ flux based on the difference between modeled and observed $\mathrm{CO}_{2}$ concentrations.

\subsection{Forward modeling}

\subsubsection{Prior fluxes and their uncertainties}

The a priori fluxes needed in the Bayesian synthesis inversion include sources from fossil fuel emissions, fire emissions, net carbon exchange between atmosphere and land, and net carbon exchange between atmosphere and ocean. These fluxes for the time period from 2000 and 2007 used in this study are the same as those used in Deng and Chen (2011) (Table 1). The fossil fuel emission field used in this study is constructed based on the fossil fuel $\mathrm{CO}_{2}$ emission inventory from 1871 to 2006 from the Carbon Dioxide Information Analysis Center (CDIAC) (Marland et al., 2009) and the EDGAR 4 databases on a $1^{\circ} \times 1^{\circ}$ grid (Olivier and Aardenne, 2005). The grid point fire emission field used in this research is from the Global Emissions Fire Database version 2 (GFEDv2) (Randerson et al., 2007; van der Werf et al., 2006). 


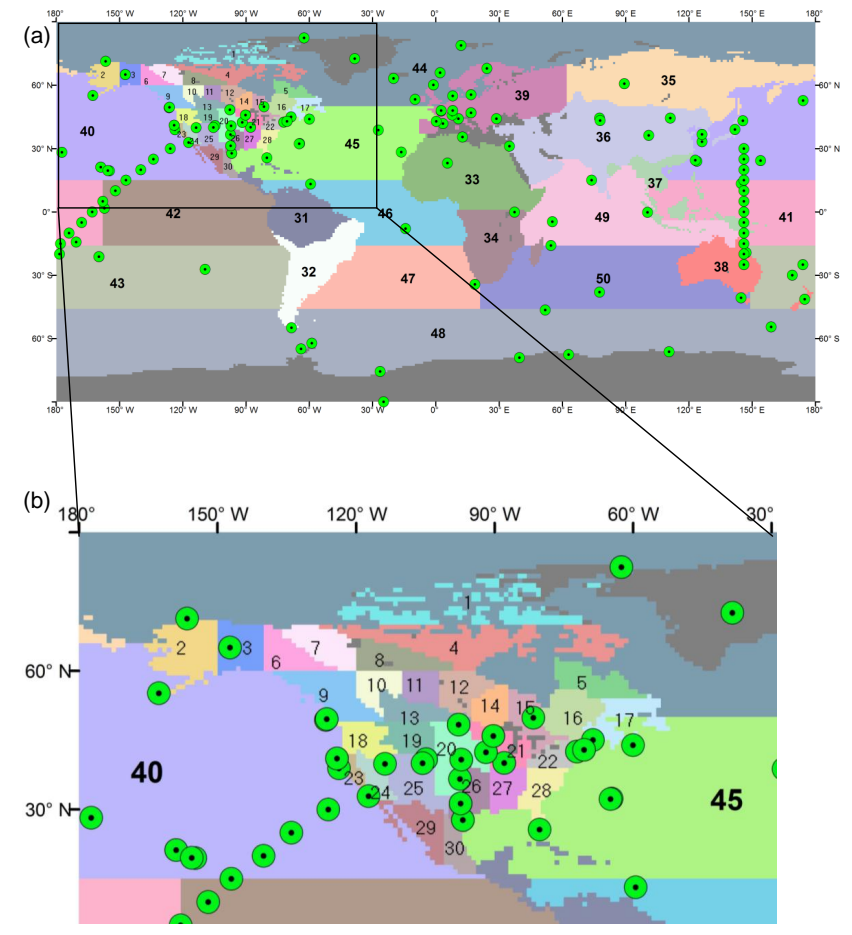

Figure 1. (a) A nested inversion system with 30 regions for North America and 20 regions for the remainder of the globe. The 210 measurement sites are indicated as circles. (b) An enlarged portion for North America.

The Boreal Ecosystem Productivity Simulator (BEPS) is employed to produce seasonally varying net ecosystem exchange (NEE) fluxes in hourly time steps globally (Chen et al., 1999, 2012; Ju et al., 2006). Developed based on FOREST Biogeochemical Cycles (FOREST-BGC) (Running and Coughlan, 1988), BEPS was originally intended for modeling the Canadian forest carbon cycle (Chen et al., 2007; Ju et al., 2006; Liu et al., 1999, 2002), but it has been extended to temperate and tropical ecosystems (Higuchi et al., 2005; Matsushita and Tamura, 2002; Sun et al., 2004; Chen et al., 2012). It uses remotely sensed leaf area index (LAI) (Deng et al., 2006), land cover type from Global Land Cover (GLC2000), meteorology from NCEP-reanalysis (Kalnay et al., 1996), and soil textural data (Webb et al., 1991). A unique feature of BEPS is the separation of sunlit and shaded components in the canopy using not only LAI but also a foliage clumping index (Chen et al., 2005; He et al., 2012) when calculating photosynthesis (Liu et al., 2002; Chen et al., 2012). Given that soil carbon pools are often not well modeled by terrestrial biosphere models, large uncertainties exist in the modeled annual carbon fluxes. However these models are still useful in estimating seasonal and diurnal patterns in response to changes in environmental conditions. Therefore, in most atmospheric inversion studies the prior annual mean NEE from land surfaces at each grid is set to zero (Gurney et al., 2004; Rödenbeck et al., 2003). The use of seasonally and diurnally varying biospheric fluxes is essential for the forward modeling to include the covariance of atmospheric transport and the surface flux (Denning et al., 1995; Gurney et al., 2004; Randerson et al., 1997; Deng and Chen, 2011).

In this study, two sets of control terrestrial biosphere fluxes from BEPS are prepared: (1) annually balanced but seasonally and diurnally varying NEE fluxes, and (2) annually, seasonally, and diurnally varying NEE fluxes. The annually balanced NEE fluxes are prepared by forcing the annual mean NEE to be zero, resulting in no interannual variability, while the seasonal and diurnal variability is retained. In fulfilling the objectives of this research, cropland carbon adjustments are made to these prior NEE fluxes (see Sect. 3).

The main processes responsible for ocean $\mathrm{CO}_{2}$ uptake is the partial pressure difference between the sea surface and the overlying air which in part depends on the seasonal growth of phytoplankton in the oceans. The daily air-sea $\mathrm{CO}_{2}$ fluxes across the sea surface in this research are simulated by the OPA-PISCES-T model, which is a global circulation model (OPA) (Madec et al., 1998) coupled with an ocean biochemistry model (PISCES-T) (Aumont, 2003; Buitenhuis et al., 2006). This coupled model is forced by daily wind stress, heat, and water fluxes from NCEP reanalysis (Kalnay et al., 1996). The ocean-atmosphere flux - along with the land-atmosphere flux, fossil emissions, and fire emissions - from 2000 to 2007 were fitted to a $1^{\circ} \times 1^{\circ}$ spatial scale at hourly time steps and aggregated to $3^{\circ} \times 2^{\circ}$ for North America and $6^{\circ} \times 4^{\circ}$ for the rest of the globe as inputs for forward modeling.

\subsubsection{Atmospheric transport}

The atmospheric transport model chosen for this research is the transport-only version of the global chemistry transport model (Krol et al., 2005) version 5 (TM5), which is an offline model driven by meteorological data from the European Centre for Medium-Range Weather Forecast (ECMWF) model. In this study, we define a global grid of $6^{\circ} \times 4^{\circ}$ with nested grids focusing on North America at $3^{\circ} \times 2^{\circ}$ based on Peters et al. (2005). The model consists of 25 vertical layers: 5 layers in the boundary layer, 10 in the free troposphere, and 10 in the stratosphere. In this study, the prior hourly fluxes are input into TM5 to generate forward simulations of hourly concentrations at $210 \mathrm{CO}_{2}$ observation sites across the globe for emissions from fossil fuel consumption $\left(\boldsymbol{c}_{\mathrm{ff}}\right)$, fire $\left(\boldsymbol{c}_{\text {fire }}\right)$, terrestrial biosphere $\left(\boldsymbol{c}_{\text {bio }}\right)$, and oceans $\left(\boldsymbol{c}_{\mathrm{oce}}\right)$.

\subsection{3 $\mathrm{CO}_{2}$ observations}

The atmospheric $\mathrm{CO}_{2}$ concentrations used in this study are the monthly $\mathrm{CO}_{2}$ observation data from 2000 to $2007 \mathrm{com}$ piled in the GLOBALVIEW- $\mathrm{CO}_{2} 2008$ database. These concentrations are not actual data but rather baseline conditions which are derived using data integration techniques described by Masarie and Tans (1995). The data set is compiled 
with different data types, including surface flask, tower, aircraft, and ship measurements. In this study, selected months that used measurement-based data from 210 stations are taken to compile the $\mathrm{CO}_{2}$ concentration matrix, and they consist of 12181 station measurements during the 8-year period from 2000 to 2007 (Fig. 1).

In order to find the concentration corresponding to the biases in the surface carbon flux to be adjusted through inverse modeling, simulated concentrations corresponding to the prior fluxes need to be subtracted from $\mathrm{CO}_{2}$ measurements. For continental tower sites, the GLOBALVIEW- $\mathrm{CO}_{2}$ data set contains weekly averages of measurements in only afternoon hours to capture the well-mixed condition within the planetary boundary layer, and therefore the monthly simulated concentrations at these sites are also taken as average values in the same afternoon hours. For non-tower sites, GLOBALVIEW-CO $\mathrm{CO}_{2}$ provides a summary of the sample collection times for discrete observations. The simulated concentrations are also sampled at the same times to obtain the monthly mean values, so as to be consistent with the GLOBALVIEW- $\mathrm{CO}_{2}$ data set. These monthly averaged simulated concentrations are then subtracted from the corresponding 12181 monthly $\mathrm{CO}_{2}$ measurements $\left(\boldsymbol{c}_{\mathrm{obs}}\right)$ from GLOBALVIEW- $\mathrm{CO}_{2}$ to produce the residual concentration (C), expressed as follows:

$\boldsymbol{c}=\boldsymbol{c}_{\mathrm{obs}}-\boldsymbol{c}_{\mathrm{ff}}-\boldsymbol{c}_{\mathrm{fire}}-\boldsymbol{c}_{\mathrm{bio}}-\boldsymbol{c}_{\mathrm{oce}}$.

This residual concentration is used as input to the inversion system to optimize the surface carbon flux.

\subsection{Inverse modeling}

\subsubsection{Inversion regions and concentration locations}

The atmospheric $\mathrm{CO}_{2}$ concentrations are used for inversion of 50 global regions, including 30 regions in North America (Fig. 1), following Deng et al. (2007) and Deng and Chen (2011). The 30 regions in North America are delineated based on a $1 \mathrm{~km}$ resolution land cover map from AVHRR (Advanced Very High Resolution Radiometer) data (DeFries and Townshend, 1994) and provincial and state boundaries. This nested inversion system allows for a reduction of errors due to spatial aggregation over the focused region of North America and in the meantime does incur excessive computation. Although the spatial resolution over North America is still relatively low, the number of regions is adequate to capture the atmospheric signal and to show the broad source and sink patterns.

\subsubsection{Time-dependent Bayesian synthesis approach}

In the time-dependent Bayesian synthesis approach (Enting, 2002) used in our inverse modeling, a linear combination of source and sink terms is formulated to match with $\mathrm{CO}_{2}$ con- centration observations:

$c=G f+A c_{0}+\varepsilon$,

where $c_{m \times 1}$ is a vector of $m$ atmospheric $\mathrm{CO}_{2}$ observations at given space and times; $\boldsymbol{\varepsilon}_{m \times 1}$ is a random error vector with a zero mean and a covariance matrix $\operatorname{cov}(\boldsymbol{\varepsilon})=\mathbf{R}_{m \times m}$; $\mathbf{G}_{m \times(n-1)}$ is a given matrix representing a transport (observation) operator, where $n-1$ is the number of fluxes to be determined; $\mathbf{A}_{m \times 1}$ is a unity vector (filled with 1) that relates to the assumed initially well-mixed atmospheric $\mathrm{CO}_{2}$ concentrations $\left(\boldsymbol{c}_{0}\right)$; and $f_{(n-1) \times 1}$ is an unknown vector of carbon fluxes of all studied regions. In this research, $m=12181$ (the number of measurements as mentioned in Sect. 2.1.3) and $(n-1)=4800$ (50 regions $\times 8$ years $\times 12$ months $)$.

After combining matrixes $\mathbf{G}$ and $\mathbf{A}$ into $\mathbf{M}_{m \times n}=(\mathbf{G}, \mathbf{A})$ and vectors $\boldsymbol{f}$ and $\boldsymbol{c}_{0}$ as $s_{n \times 1}=\left(\boldsymbol{f}^{T}, \boldsymbol{c}_{0}\right)^{T}$, Eq. (2) is rewritten as

$c=\mathbf{M} s+\varepsilon$.

while Eq. (3) can be solved for $s$ by the conventional leastsquared technique, the problem is poorly constrained. The Bayes approach (Tarantola, 2005) is generally used for illconstrained problems through introducing a priori information in the inversion process. The best a priori information for this purpose is a prior estimate of the surface flux. The a posteriori flux is obtained by minimizing the following cost function $J$ :

$J=\frac{1}{2}(\mathbf{M} s-c)^{T} R^{-1}(\mathbf{M} s-c)+\frac{1}{2}\left(s-s_{\mathrm{p}}\right)^{T} \mathbf{Q}^{-1}\left(s-s_{\mathrm{p}}\right)$,

where $s_{\mathrm{p}_{n} \times 1}$ is the a priori estimate of $s$ (set to zero after subtracting its contribution to concentration from the atmospheric $\mathrm{CO}_{2}$ observation); the covariance matrix $\mathbf{Q}_{n \times n}$ represents the uncertainty in the a priori estimate; and $R_{m \times m}$ is the model-data mismatch error covariance. Through minimizing this cost function in Eq. (4), the posterior best estimate of $s$ (Enting, 2002) is defined as

$\hat{s}=\left(\mathbf{M}^{T} R^{-1} \mathbf{M}+\mathbf{Q}^{-1}\right)^{-1}\left(\mathbf{M}^{T} R^{-1} \boldsymbol{c}+\mathbf{Q}^{-1} s_{\mathrm{p}}\right)$,

with the posterior uncertainty expressed as follows:

$\hat{\boldsymbol{Q}}=\left(\mathbf{Q}^{-1}+\mathbf{M}^{T} R^{-1} \mathbf{M}\right)^{-1}$.

\subsubsection{Transport (observation) operator, model-data mismatch, and prior uncertainties}

The matrices for transport (observation) operator, $\mathbf{M}$; the model-data mismatch, $R$; and the prior uncertainties, $\mathbf{Q}$, are taken from Deng and Chen (2011). The transport (observation) operator, $\mathbf{M}$, is formed from 4800 forward simulations (8 years and 50 regions). An initial flux of $1 \mathrm{Pg} \mathrm{C}$ for each month and region was prescribed in the TM5 transport model to find the monthly contribution of each region to $\mathrm{CO}_{2}$ 
concentration at each observation site. The model-data mismatch, $R$, reflects the difference between the modeled and the observed $\mathrm{CO}_{2}$ concentrations, which include both errors from transport modeling and measurement (such as instrument errors). The observation sites were divided into five categories, each with its own constant portion $\left(\sigma_{\text {const }}\right)$ and variable portion (GVsd) that is computed monthly from the standard deviation data given in GLOBALVIEW-CO 2008 variation (var) files. The constant portion is defined under the following categories: Antarctic sites (0.15), oceanic sites (0.30), land and tower sites (1.25), mountain sites (0.90), and aircraft samples (0.75). The variable portion is the statistical summary of average atmospheric variability for each measurement record. Therefore, the covariance matrix, $\mathbf{R}$, is given as a diagonal matrix that contains the error for each month $i$ :

$\mathbf{R}_{i i}=\sigma_{\text {const }}^{2}+\mathrm{GVsd}^{2}$.

Additionally, a weighting factor, $\mathbf{W}$, is inserted to the cost function in Eq. (4) to account for the vertical correlation between measurements at different levels of the same tower and aircraft sites (i.e., smaller weights are given to each of the measurements at the same site) (Deng and Chen, 2011).

$$
\begin{aligned}
J= & \frac{1}{2}((\mathbf{M} s-\boldsymbol{c}) W)^{T} R^{-1}((\mathbf{M} s-\boldsymbol{c}) W) \\
& +\frac{1}{2}\left(s-s_{\mathrm{p}}\right)^{T} \mathbf{Q}^{-1}\left(s-s_{\mathrm{p}}\right)
\end{aligned}
$$

The weight, $W$, is a diagonal matrix with the diagonal terms given by

$w_{i i}=1 /(1+0.6(n-1))$,

where $n$ is the number of observations at different levels at the same site.

While the a priori fluxes are set to zero after subtracting their contributions toward the measured $\mathrm{CO}_{2}$ concentrations, the a priori uncertainties, $\mathbf{Q}$, are important in forcing the spatial distribution of the inverted fluxes (Table 1). The uncertainties for fossil fuel of $\pm 6 \%$ (Marland et al., 2009) and for fire fluxes of $\pm 20 \%$ (van der Werf et al., 2010) are not included in $\mathbf{Q}$, and hence, it is important to note that the inverted fluxes are subject to these additional uncertainties.

The $\chi^{2}$ test (Gurney et al., 2003) is employed to test the consistency of the fit to $\mathrm{CO}_{2}$ data and the prior flux estimate simultaneously:

$\chi^{2}=\frac{J_{\min }}{N_{\mathrm{obs}}}=\frac{\sum_{m=1}^{m} \frac{(\mathbf{M} s-c)^{2}}{R^{2}}+\sum_{n=1}^{n} \frac{\left(s-s_{\mathrm{p}}\right)^{2}}{\mathbf{Q}^{2}}}{N_{\mathrm{obs}}}$,

where $N_{\mathrm{obs}}$ is the number of degrees of freedom and $J_{\min }$ is the cost function from Eq. (4). The consistency of the fit is highest when the value of $\chi^{2}$ equals unity.

\section{US cropland carbon integration methodology}

During the growing season, cropland in the US Midwest represents a strong regional carbon sink. However, a large portion of crop biomass is removed during harvest and transported to other regions for processing and consumption. When the crop products are consumed by humans and livestock, $\mathrm{CO}_{2}$ is released back into the atmosphere at geographic locations that differ from the origin of production. In this study, these lateral redistributions of carbon are considered in the prior fluxes used in atmospheric $\mathrm{CO}_{2}$ inversion studies in order to investigate their influence on the inverted carbon source and sink distribution.

\subsection{US cropland carbon budget based on inventory data}

The regional patterns of $\mathrm{CO}_{2}$ uptake and release in US croplands based on agricultural statistics (West et al., 2011) are used to adjust the prior biosphere flux used in our inversion. The data include county-level net primary productivity (NPP), harvest, and changes in soil carbon from 1990 to 2008, as well as human and livestock crop consumption from 2000 to 2008 (CDIAC, 2014). The national crop carbon budget for the USA from 2000 to 2008 is balanced within 0.3 to $6.1 \% \mathrm{yr}^{-1}$ based on the study from West et al. (2011). Although many other important components are included in the overall US cropland carbon budget, such as exports and crop carbon used for fuel, the vertical net carbon exchange (NCE) into the atmosphere is given by the sum of net carbon uptake from NPP, net change in soil carbon, and the release of carbon from biomass decomposition, human consumption, and livestock consumption.

\subsubsection{Crop NPP, harvest, biomass decomposition, and changes in soil carbon pool}

The cropland NPP used in West et al. (2011) is calculated based on annual statistics of crop production $(P)$ in units of tons of biomass and harvested crop area (HA) reported by the US Department of Agriculture (USDA) National Agricultural Statistics Service. County-level statistics are gapfilled using district-level data and then converted to countylevel NPP in units of carbon using Eq. (11), which is documented in earlier studies (Hicke, 2004; Hicke and Lobell, 2004; Prince et al., 2001; West et al., 2010):

$\mathrm{NPP}_{\text {crops }}=\sum_{i} \frac{P_{i} \times\left(1-\mathrm{MC}_{i}\right) \times C}{\mathrm{HI}_{i} \times f_{\mathrm{AG}, i} \times \mathrm{HA}_{i}}$,

where $P$ is the reported crop production; MC is the harvest moisture content; $C$ is the conversion factor from biomass to carbon ( $0.45 \mathrm{~g}$ of $\mathrm{C}$ per $\mathrm{g}$ of dry mass); $\mathrm{HI}$ is the harvest index, i.e., the ratio of yield mass to aboveground biomass; $f_{\mathrm{AG}}$ is the fraction of production allocated aboveground; and the subscript $i$ indicates 17 different crops (corn, soybean, 

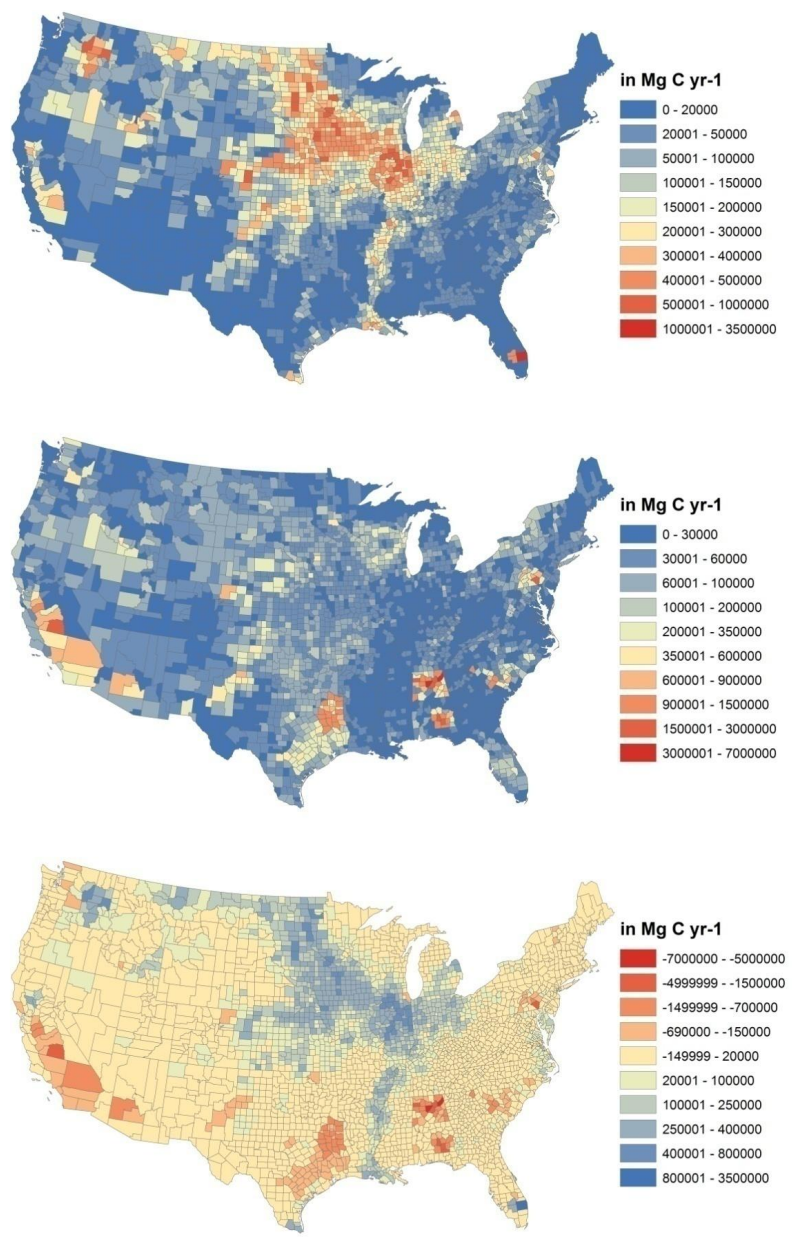

Figure 2. Spatial distributions of annual crop production (top); crop consumption (middle); and crop NEP (bottom) for 2003. Data from CDIAC (2014).

oats, barley, wheat, sunflower, hay, sorghum, cotton, rice, peanuts, potatoes, sugar beets, sugarcane, tobacco, rye, and beans) representing the majority of the crops grown in the conterminous US (West et al., 2010, 2011). The harvested amount is calculated based on crop yields. Carbon released from biomass decomposition is calculated from NPP by subtracting the amount that is harvested. The remainder of crops, i.e., the amount not harvested, is left as residue and is either sequestered into the soil or decomposed within the same year.

Changes in soil carbon are calculated based on empirical relationships between land management practices and soil carbon change (West et al., 2008). In order to capture the long-term impacts on soil carbon pools from a 20-year history of changes in crop rotation and tillage intensity, the soil carbon change was calculated from 1980 to 2008 .

\subsubsection{Human and livestock consumption}

Human crop carbon consumption data provided by West et al. (2011) were calculated based on the per capita food con- sumption and the US population census data. The livestock consumption data were calculated in a similar way but also considered different feed consumption rates of different animal species. The consumed amount was assumed to be released back into the atmosphere within the same year as $\mathrm{CO}_{2}$ through respiration, excretion, and flatus (West et al., 2009). Excretion typically entered the waste treatment facilities within the county, and the emissions were taken into account in the consumption term above.

\subsection{Prior flux adjustments for US croplands}

One way to integrate the carbon exchange of crops into the inversion model is to adjust the prior NEP modeled by BEPS. As part of the crop carbon exchange, the harvested amount is taken away from the field and respired back to the atmosphere when consumed by humans, $R_{\text {human_consumption, }}$ and livestock, $R_{\text {livestock_consumption. Therefore, crop NEP is given }}$ by

$$
\begin{aligned}
& \mathrm{NEP}_{\text {crop }}=\mathrm{NPP}_{\text {crop }}-R_{\mathrm{h} \text {, residue }}-R_{\text {human_consumption }} \\
& \quad-R_{\text {livestock_consumption }}+\Delta \boldsymbol{c}_{\text {soil }} .
\end{aligned}
$$

Since the residue amount, including both the remaining aboveground and belowground biomass, is the difference between the total crop biomass and the amount harvested, Eq. (12) can be rewritten as:

$$
\begin{aligned}
& \mathrm{NEP}_{\text {crop }}=\mathrm{NPP}_{\text {harvested }}+\Delta \boldsymbol{c}_{\text {soil }}-R_{\text {human_consumption }} \\
& \quad-R_{\text {livestock_consumption }}=\text { production-consumption, }
\end{aligned}
$$

where

production $=\mathrm{NPP}_{\text {harvested }}+\Delta \boldsymbol{c}_{\text {soil }}$,

consumption $=R_{\text {human_consumption }}$

$$
+R_{\text {livestock_consumption }} \text {. }
$$

The spatial patterns of crop production, consumption, and NEP are shown in Fig. 2. The spatial distributions of crop production and consumption are calculated monthly and are used to adjust the monthly NEP distributions modeled by BEPS over the conterminous US. The production and consumption terms are adjusted separately due to their different seasonal patterns.

\subsubsection{Production adjustment}

The simulated terrestrial NPP by BEPS is adjusted to integrate cropland production over the contiguous US using the following equation:

$$
\begin{aligned}
& \mathrm{NPP}_{\text {adjusted }}=\mathrm{NPP}_{\text {biosphere }}-r_{\text {crop_area }} \cdot\left(\mathrm{NPP}_{\text {biosphere }}\right) \\
& \quad+\text { production }=\left(1-r_{\text {crop_area }}\right) \cdot \mathrm{NPP}_{\text {biosphere }} \\
& \quad+\text { production }=\left(1-r_{\text {crop_area }}\right) \cdot \mathrm{NPP}_{\text {biosphere }} \\
& \quad+\mathrm{NPP}_{\text {harvested }}+\Delta \boldsymbol{c}_{\text {soil }},
\end{aligned}
$$

where $\mathrm{NPP}_{\text {biosphere }}$ is the $1^{\circ} \times 1^{\circ} \mathrm{NPP}$ output from BEPS and $r_{\text {crop_area }}$ is the ratio of harvested crop area within the $1^{\circ} \times 1^{\circ}$ 
grid over the total area of the grid. The county-level cropland production is first extrapolated into a mean value for each $1^{\circ} \times 1^{\circ}$ grid and then adjusted using Eq. (16). The ratio $r_{\text {crop_area }}$ is calculated based on the harvested area data. The basic idea of Eq. (16) is to replace BEPS NPP with more accurate crop production data for the portion of land area that is used for crop production, while BEPS NPP is unchanged for the remaining area. In this way, both the productive and nonproductive areas in a grid are included in the prior, and the simulation of non-crop area by BEPS may be influenced by adjacent crop areas. BEPS uses GLC2000 as the land cover data in NPP simulations, but these data are not as accurate as the agricultural crop area statistics within each grid. Chan and Lin (2011) cautioned researchers against the direct comparison of carbon accounting based on agricultural census data and fluxes simulated by biospheric models due to large differences of different land cover classifications used by the models. For this reason, we choose to use the crop area ratio method for the production adjustment.

Since the prior surface $\mathrm{CO}_{2}$ fluxes enter into the atmospheric transport model on hourly time steps, the annual crop carbon production data are interpolated into the seasonal and diurnal patterns simulated by BEPS. Firstly, the annual $\mathrm{NPP}_{\text {biosphere }}$ is converted to annual $\mathrm{NPP}_{\text {adjusted }}$, and the ratio between the two is taken and multiplied by the hourly $\mathrm{NPP}_{\text {biosphere }}$ fluxes, resulting in hourly adjusted fluxes from 2000 to 2008 for each $1^{\circ} \times 1^{\circ}$ grid.

\subsubsection{Consumption adjustment}

The consumption terms are integrated into BEPS-simulated $R_{\mathrm{h}}$ over the contiguous US using the following equation:

$$
\begin{aligned}
& R_{\mathrm{h}, \text { adjusted }}=R_{\mathrm{h}, \text { biosphere }}-r_{\text {crop_area }} \cdot\left(R_{\mathrm{h}, \text { biosphere }}\right) \\
& \quad+\text { consumption }=\left(1-r_{\text {crop_area }}\right) \cdot R_{\mathrm{h} \text {, biosphere }} \\
& \quad+\text { consumption }=\left(1-r_{\text {crop_area }}\right) \cdot R_{\mathrm{h} \text {, biosphere }} \\
& \quad+R_{\text {human_consumption }}+R_{\text {livestock_consumption }},
\end{aligned}
$$

where $R_{\mathrm{h}}$, biosphere is the $1^{\circ} \times 1^{\circ} R_{\mathrm{h}}$ output from BEPS and $r_{\text {crop_area }}$ is the ratio of harvested crop area within the $1^{\circ} \times 1^{\circ}$ grid over the total area of the grid. The county-level cropland consumption data are first resampled into each $1^{\circ} \times 1^{\circ}$ grid, and the mean value of each grid is used to adjust $R_{\mathrm{h}}$ using Eq. (17). However, unlike the production adjustment, the temporal patterns of $\mathrm{CO}_{2}$ release from human and livestock consumptions do not follow the seasonal and diurnal patterns simulated for the biosphere. We therefore assume constant hourly release of $\mathrm{CO}_{2}$ from crop consumption throughout the year. In this way, the annual consumption amount is divided equally into the hourly values and added to the hourly simulated $R_{\mathrm{h}}$, biosphere from BEPS for the time period from 2000 to 2008 at each $1^{\circ} \times 1^{\circ}$ grid.

\subsection{Schemes of inversion experiments}

Two sets of inversion experiments (Table 2) are designed to test for the impact of integrating the cropland carbon data into the prior terrestrial flux. In the first set (Experiments $1 \mathrm{a}, 1 \mathrm{~b}, 1 \mathrm{c})$, the monthly terrestrial biosphere NEP modeled by BEPS at hourly time steps is first neutralized on an annual basis, meaning that the annual mean terrestrial flux is 0 for each grid cell but its seasonal variation is retained. The neutralized flux is then adjusted for crop production and consumption in Experiments $1 \mathrm{~b}$ and 1c. After these adjustments, the annual prior flux in Experiments $1 \mathrm{~b}$ and 1c (Table 3) differs from zero. The prior terrestrial surface flux in many atmospheric inversion studies only contains seasonal instead of interannual variations (Gurney, 2004; Rödenbeck et al., 2003) in order to minimize the influence of the errors in the prior flux on the inverted annual flux so that the results are mostly based on the "atmospheric view". In the second set (Experiments 2a, 2b, 2c), the same monthly BEPS NEP is used without annual neutralization (Table 3) so that both seasonal and interannual variations in NEP are retained and the best estimate of the biospheric carbon flux is used to constrain the inversion. Experiments $1 \mathrm{a}-\mathrm{c}$ are therefore designed to explore the strength of the carbon cycle signal in the atmospheric $\mathrm{CO}_{2}$ measurement, while Experiments $2 \mathrm{a}-\mathrm{c}$ are considered to be the best final estimates by integrating ecosystem modeling results and crop statistics. In each set of experiments, there is a control run (Experiments 1a, 2a), which is used to assess influences of the production adjustment (Experiments $1 b, 2 b$ ) and influences of the combined production and consumption adjustments (Experiments 1c, 2c) on the inverted flux.

The a priori uncertainty matrix $\mathbf{Q}$ described in Sect. 2.2.3 is adjusted to take into account uncertainties from the cropland production and consumption data. Uncertainties in the agricultural production data consist of parameter uncertainties associated with the harvest index (HI) and reported crop production $(P)$ (Chan and Lin, 2011). Bolinder et al. (2007) and Prince et al. (2001) show the standard deviation of HI, the dominant source of uncertainty towards NPP, to be $10 \%$. Therefore, experiments that adjust for production only are prescribed a $10 \%$ uncertainty in annual NPP distributed over the production regions and weighted with the original matrix Q. Experiments that adjust for both production and consumption use the above method to include production uncertainty as well as an additional $1 \%$ of annual total human consumption (West et al., 2009) and $20 \%$ of the annual total livestock consumption distributed over consumption areas (Ciais et al., 2007). Additionally, the $\chi^{2}$ test (Eq. 12) is employed to show the consistency of the fit to data and prior flux estimates simultaneously. The $\chi^{2}$ test indicates that experiments $1 \mathrm{c}$ and $2 \mathrm{c}$, having the $\chi^{2}$ values closest to unity, have the greatest consistency. 

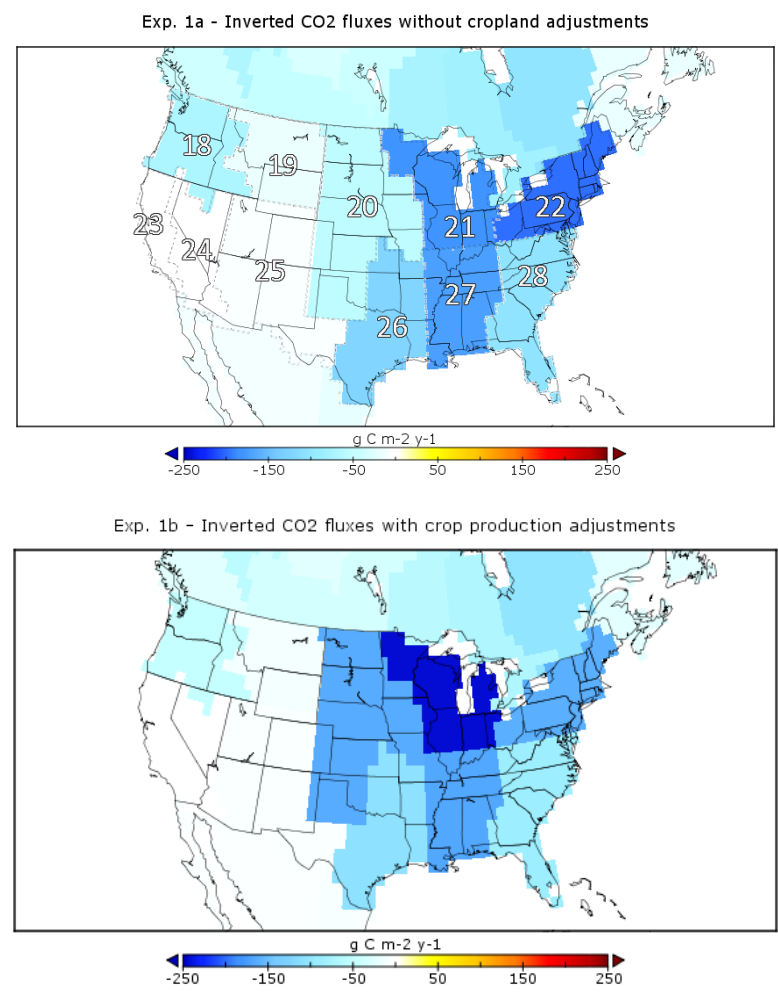

Exp. 1c - Inverted CO2 fluxes with crop production and consumption adjustments

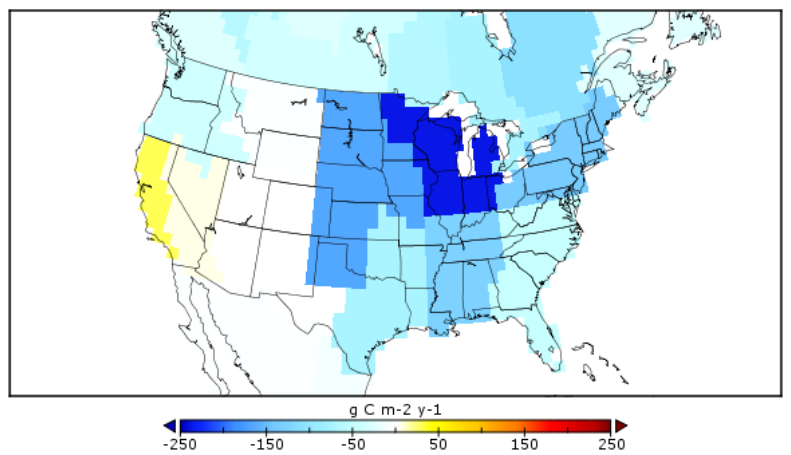

Figure 3. Map of mean annual inverted $\mathrm{CO}_{2}$ flux for experiment 1 during 2002 to 2007 over contiguous US regions. Negative values represent carbon uptake.

\section{Results and discussion}

The inversion experiments described in Sect. 3.3 are conducted to test the impacts of cropland inventory on the inverted $\mathrm{CO}_{2}$ fluxes. The impacts are evaluated based on the multi-year mean annual values and seasonal variations.

\subsection{Multi-year regional carbon budget}

\subsubsection{Average annual flux}

The average annual inverted $\mathrm{CO}_{2}$ fluxes over the conterminous US are reported for experiment 1 (Fig. 3) and experi- ment 2 (Fig. 4). Table 4 summarizes the mean inverted $\mathrm{CO}_{2}$ fluxes $(\mu)$ and errors $(\varepsilon)$, as well as the percentage changes $(\Delta \%)$ from the control case calculated by

$\Delta \%=\frac{\mu-\mu_{\text {control }}}{\mu_{\text {control }}}$,

where $\mu_{\text {control }}$ is the annual mean inverted flux for the corresponding control experiment.

To evaluate the impact of integrating crop production and consumption data into the prior fluxes, comparisons of the inverted fluxes can be made between the experiments with and without crop adjustments. However, in order for these comparisons to be meaningful, a signal-to-noise ratio (SNR) is calculated for each region, using the following equation:

$\mathrm{SNR}=\frac{\left|\mu-\mu_{\text {control }}\right|}{\varepsilon}$,

where $\varepsilon$ is the posterior uncertainty in the inverted flux for a region. Note that the "signal" is defined here as the mean difference in the inverted fluxes between the control and a crop-adjusted experiment, in order to represent the signal introduced by the adjustment. If SNR is less than unity, the resulting change due to an agricultural adjustment is less than the uncertainty, and hence the signal is within the noise level of the results. In Table 4, regions with SNR greater than unity are denoted with an asterisk.

Comparing Fig. 3a and b, it can be seen that the production adjustment redistributed the carbon sink from forested regions in the southeast (regions 26 to 28) and northwest (regions 18,19$)$ to cropland area in the Midwest (regions 20 and 21). SNR for experiment $1 \mathrm{~b}$ for region 20 is greater than 1 (Table 4), indicating that the sink increase in this region is beyond inversion uncertainty. The increase in the sink size in the US Midwest can be attributed to the large $\mathrm{CO}_{2}$ uptake during the growing season, but much of the carbon is released through crop consumption in other geographic locations. Seasonal results for these regions are shown in Sect. 4.1.3.

The impact of crop consumption adjustment on the inversion result can be assessed by comparing Fig. $3 \mathrm{~b}$ and c. In region 28 with large crop consumption, the inverted carbon sink (Fig. 3c) is reduced by $68 \%$ from the case with crop production adjustment only (Fig. $3 \mathrm{~b}$ ) and by $76 \%$ from the control case (Fig. 3a), which is a sink of $69 \mathrm{Tg} \mathrm{C} \mathrm{yr}^{-1}$ (Table 4). In regions 23 and 24 with large crop consumption and low vegetation growth, the crop consumption adjustment turns weak carbon sinks (Fig. 3a and b) into sources (Fig. 3c). SNR for experiment 1c for region 24 (California) is greater than 1 , confirming that this shift from sink to source is beyond the inversion uncertainty. In general, crop consumption adjustment in regions with considerable consumptions (regions 18, 19, 23, 24, 25, 26, 27, 28) induces noticeable reduction in the carbon sink. It would also be interesting to note that the crop production adjustment (experiment $1 \mathrm{~b}$ ) increases the USA sink by $44 \%$ but decreases the 
Canadian sink by $15 \%$, and the crop production and consumption adjustments (experiment 1c) reduce the sink by 1.4 and $12.1 \%$ for USA and Canada, respectively, relative to the control case (experiment 1a, Table 4). These results suggest that the crop information used in the inversion affects not only US carbon sinks but also neighboring regions (such as Canada). The inverted results from both crop production and consumption adjustments (experiment 1c, Fig. 3c) show that the US Midwest sink in $2002-2007$ is $425 \pm 129 \mathrm{Tg} \mathrm{C} \mathrm{yr}^{-1}$. This sink value obtained in experiment $1 \mathrm{c}$ is smaller than that $\left(522 \mathrm{Tg} \mathrm{C} \mathrm{yr}^{-1}\right)$ in experiment $1 \mathrm{~b}$ but considerably larger than that $\left(189 \mathrm{Tg} \mathrm{C} \mathrm{yr}^{-1}\right)$ in the control case, confirming the importance of considering the crop production and consumption data for atmospheric inversion.

Experiments $1 \mathrm{a}-\mathrm{c}$ analyzed above are designed to accentuate the information content of atmospheric $\mathrm{CO}_{2}$ measurements for the surface carbon flux by neutralizing the annual biospheric flux before making the crop consumption adjustments. However, it could be argued that the annually neutralized fluxes may not be the best prior information for constraining the inversion. Experiments $2 \mathrm{a}-\mathrm{c}$ are therefore conducted with the best prior estimates possible based on a biospheric model and crop data. The prior biospheric carbon flux used in experiment 2 differs from that in experiment 1 in the following ways: (1) the annual net carbon flux modeled by BEPS is used without neutralization, (2) the interannual variations in the prior flux are considered, and (3) the interannual variations in crop production and consumption are also considered. Although errors in the annual mean prior fluxes would have imprints on the inverted results in experiment 2 , the unneutralized fluxes may nudge the inverted results closer to reality as they integrate prior knowledge on the carbon source and sink distribution and the interannual variability.

Figure 4 shows inverted results under experiment 2 with comparisons to the prior estimates. The production adjustment (experiment $2 b$ ) leads to significant increases in the $\mathrm{CO}_{2}$ sink in the Midwest crop area (region 20). Regions 19, 21 , and 25 also gain noticeable sink increases, but sinks in other regions in the US decrease in compensation for these gains. Relative to experiment $2 b$, the additional consumption adjustment made in experiment $2 \mathrm{c}$ significantly weakened the sinks in the west region and noticeably in the southeast. These results are consistent with the findings from experiment 1 . Crop adjustments in experiment 2 greatly enhanced the sinks in the cropland in the US Midwest (regions 20,21), mostly at the expense of forested areas in the southeast (regions $26,27,28$ ). This is also similar to experiment 1 , which only takes into account the seasonal variations and not the interannual variations. For the purpose of comprehensive evaluation of how crop adjustments spatially redistribute the carbon flux, Table 5 provides a matrix of correlation coefficients of the change in the inverted flux from experiment $2 \mathrm{a}$ to experiment $2 \mathrm{c}$ among the 11 regions in the US, where positive correlations indicate that crop adjustments make the inverted flux increase or decrease in the same direction. Region 21, for example, is negatively correlated with most regions except regions 20,23, and 24, suggesting that its increase in carbon sink after the crop adjustments is mostly balanced by decreases in other regions except regions 20, 23, and 24 . Another interesting example is region 28, which is strongly and negatively correlated with the Midwest region 21 and strongly and positively correlated to the west regions 18,19 , and 25. A large part of these correlations is due to adjustments to the priors (Table 3), as the change in the inverted flux for a region is highly correlated with the adjustment to the region (Fig. 6). However, atmospheric circulation patterns, such as the westerly and the monsoon air flows (air mass moving from the southeast to the Midwest), could also have impacts on these correlations.

The spatial distributions of the prior and posterior fluxes for the three pairs shown in Fig. 4 are visually well correlated. As an example, the correlation between the prior and posterior fluxes of experiment $2 \mathrm{a}$ is shown in Fig. 5a. It is highly significant $\left(r^{2}=0.92\right)$, meaning that the inverted flux distribution among the regions is highly correlated with the prior flux used to constrain the inversion. It is interesting to note that the posterior fluxes of the various regions are about 1.6 times their prior fluxes, suggesting that atmospheric inversion forces the fluxes in all regions in the conterminous US to increase in about the same proportion, which is perhaps determined according to the balance of the US with other large regions. This means that the overall magnitude of the US sink is more or less determined globally while the spatial sink pattern within the US is correlated with the prior. Figure $5 \mathrm{~b}$ further affirms this point by demonstrating that the changes in the posterior flux in experiment $2 \mathrm{c}$ are also highly correlated with the adjustments made to the prior flux. It is interesting to note that the changes are also about 1.6 times the adjustments, indicating the same strength of the influence of the adjustments to the prior on the inversion. Strong correlations between the prior and posterior exist in all experiments $\left(r^{2}=0.85-0.95\right)$. However, these strong correlations should not be taken as an indication of the sole importance of the prior in determining the posterior as it can be argued that the correlation is good because the prior flux distribution matches with the atmospheric signal. Figure $5 \mathrm{c}$ is shown to demonstrate that the posterior flux of experiment $2 \mathrm{c}$ is significantly correlated $\left(r^{2}=0.63\right)$ with the posterior flux of experiment $1 \mathrm{a}$ which is obtained with a neutralized prior and arguably represents the atmospheric signal. This correlation means that the atmospheric signal is responsible for about $63 \%$ of the spatial distribution of the inverted flux. Figure $5 \mathrm{~d}$ shows that the posterior flux from experiment 2 a constrained with a prior without the crop adjustments is highly correlated with the posterior flux from experiment 1a. This high correlation indicates that the unneutralized prior flux does not provide much additional information for inverting the spatial distribution of the carbon flux. It also indicates that the atmospheric signal is not strong enough to sense all the sinks in crop production areas. These correlations demonstrate that 
Table 2. Schemes of experiments designed to test for the impact of integrating information from crop production and consumption data into the prior fluxes.

\begin{tabular}{llr}
\hline Experiment 1. & Annually balanced terrestrial biosphere & $\chi^{2}$ \\
\hline (a) & Neutralized terrestrial prior fluxes from BEPS model (annual mean $=0$ ) \\
(b) & Neutralized terrestrial prior fluxes (annual mean =0) adjusted for crop production & 1.09 \\
(c) & Neutralized terrestrial prior fluxes (annual mean =0) adjusted for crop production & 1.12 \\
& and crop consumption (added to the prior fluxes as a source) & 0.97 \\
\hline Experiment 2. & Interannual variability in terrestrial biosphere & $\chi^{2}$ \\
\hline (a) & Terrestrial prior fluxes from BEPS model (annual mean $\neq 0$ ) & 1.11 \\
(b) & Terrestrial prior fluxes (annual mean $\neq 0$ ) adjusted for crop production & 1.16 \\
(c) & Terrestrial prior fluxes (annual mean $\neq 0$ ) adjusted for crop production and crop consumption & 0.97 \\
\hline
\end{tabular}
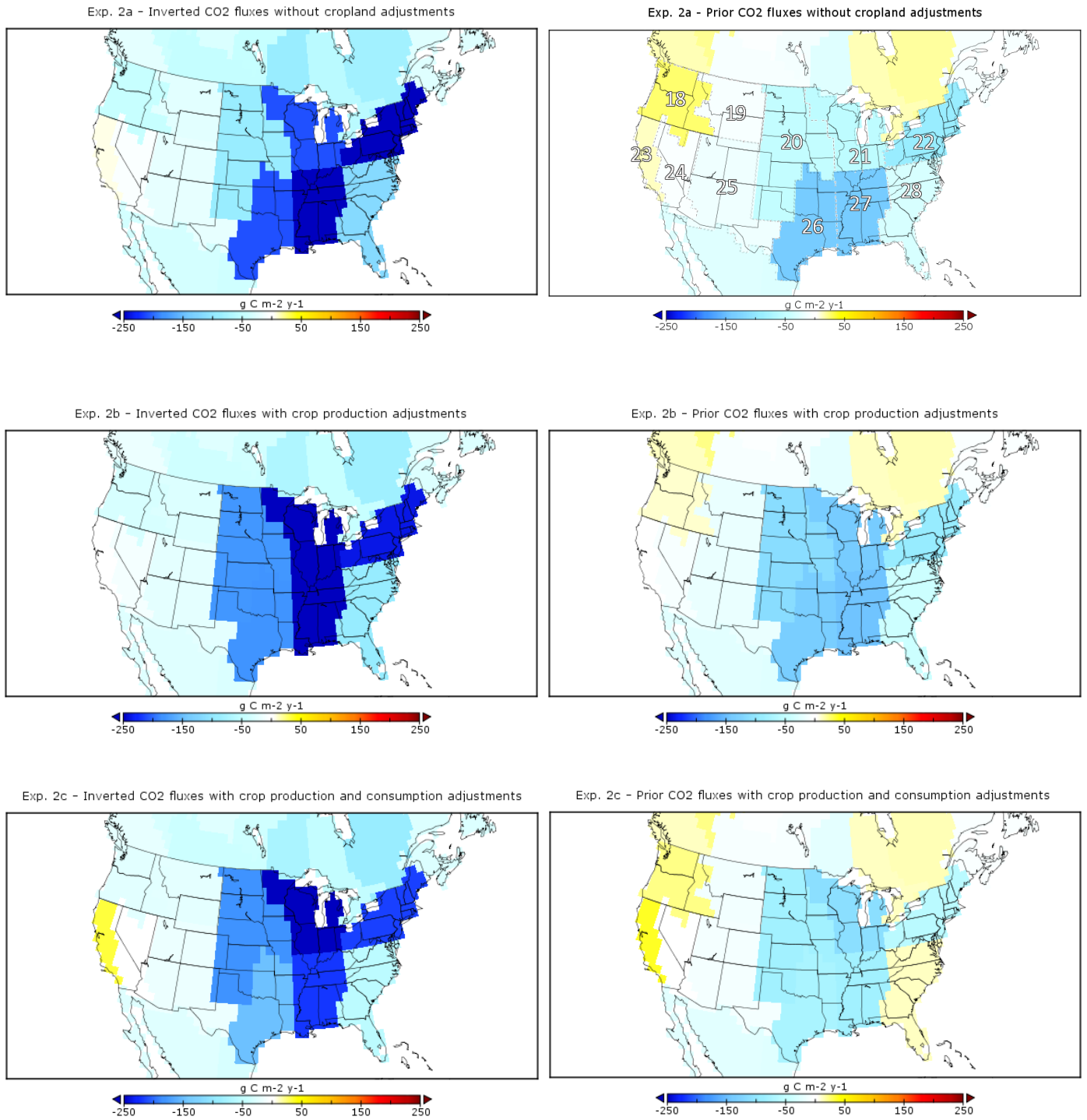

Figure 4. Map of mean annual inverted (left) and prior (right) $\mathrm{CO}_{2}$ flux for experiment 2 during 2002 to 2007 over the contiguous US. Negative values represent carbon uptake. 
Table 3. Prior fluxes used in the two sets of inversion experiments

\begin{tabular}{|c|c|c|c|c|c|c|}
\hline \multirow[t]{2}{*}{ Region } & \multicolumn{3}{|c|}{ Experiment 1} & \multicolumn{3}{|c|}{ Experiment 2} \\
\hline & $\mathrm{a}$ & $\mathrm{b}$ & $\mathrm{c}$ & $\mathrm{a}$ & $\mathrm{b}$ & $\mathrm{c}$ \\
\hline 18 & $0 \pm 6.5$ & $-8.91 \pm 8.3$ & $-1.94 \pm 9.5$ & $15.88 \pm 6.5$ & $6.97 \pm 8.3$ & $13.94 \pm 9.5$ \\
\hline 19 & $0 \pm 2.9$ & $-6.35 \pm 3.7$ & $-1.96 \pm 4.4$ & $-5.69 \pm 2.9$ & $-12.04 \pm 3.7$ & $-7.65 \pm 4.4$ \\
\hline 20 & $0 \pm 8.6$ & $-75.83 \pm 27.4$ & $-37.47 \pm 32.9$ & $-66.51 \pm 8.6$ & $-142.34 \pm 27.4$ & $-103.98 \pm 32.9$ \\
\hline 21 & $0 \pm 8.5$ & $-51.75 \pm 18.2$ & $-34.97 \pm 20.3$ & $-34.71 \pm 8.5$ & $-86.46 \pm 18.2$ & $-69.69 \pm 20.3$ \\
\hline 22 & $0 \pm 9.6$ & $-0.42 \pm 11.6$ & $17.56 \pm 13.6$ & $-49.03 \pm 9.6$ & $-49.45 \pm 11.6$ & $-31.47 \pm 13.6$ \\
\hline 23 & $0 \pm 3.0$ & $-1.93 \pm 3.9$ & $5.38 \pm 6.2$ & $2.75 \pm 3.0$ & $0.82 \pm 3.9$ & $8.12 \pm 6.2$ \\
\hline 24 & $0 \pm 0.7$ & $-1.14 \pm 1.8$ & $3.80 \pm 5.5$ & $-2.95 \pm 0.7$ & $-4.09 \pm 1.8$ & $0.85 \pm 5.5$ \\
\hline 25 & $0 \pm 3.0$ & $-3.97 \pm 3.8$ & $3.39 \pm 5.1$ & $-16.78 \pm 3.0$ & $-20.75 \pm 3.8$ & $-13.40 \pm 5.1$ \\
\hline 26 & $0 \pm 12.5$ & $3.02 \pm 15.1$ & $48.67 \pm 23.0$ & $-105.11 \pm 12.5$ & $-102.09 \pm 15.1$ & $-56.45 \pm 23.0$ \\
\hline 27 & $0 \pm 14.9$ & $-4.86 \pm 20.0$ & $36.57 \pm 26.6$ & $-88.63 \pm 14.9$ & $-93.49 \pm 20.0$ & $-52.06 \pm 26.6$ \\
\hline 28 & $0 \pm 15.6$ & $-4.69 \pm 18.7$ & $29.87 \pm 24.9$ & $-21.50 \pm 15.6$ & $-26.19 \pm 18.7$ & $8.37 \pm 24.9$ \\
\hline West & $0 \pm 4.2$ & $-22.29 \pm 5.4$ & $8.66 \pm 7.2$ & $-6.79 \pm 4.2$ & $-29.09 \pm 5.4$ & $1.86 \pm 7.2$ \\
\hline Midwest & $0 \pm 8.6$ & $-127.56 \pm 23.3$ & $-72.43 \pm 27.3$ & $-101.22 \pm 8.6$ & $-228.79 \pm 23.3$ & $-173.66 \pm 27.3$ \\
\hline Northeast & $0 \pm 9.6$ & $-0.35 \pm 11.6$ & $17.56 \pm 13.6$ & $-49.03 \pm 9.6$ & $-49.45 \pm 11.6$ & $-31.47 \pm 13.6$ \\
\hline Southeast & $0 \pm 14.3$ & $-6.53 \pm 18.1$ & $115.11 \pm 24.9$ & $-215.24 \pm 14.3$ & $-221.77 \pm 18.1$ & $-100.14 \pm 24.9$ \\
\hline US & $0 \pm 9.9$ & $-156.83 \pm 16.1$ & $68.87 \pm 20.0$ & $-372.28 \pm 9.9$ & $-529.11 \pm 16.1$ & $-303.41 \pm 20.0$ \\
\hline Canada & $0 \pm 5.9$ & $0.00 \pm 5.9$ & $0.00 \pm 5.9$ & $50.75 \pm 5.9$ & $50.75 \pm 5.9$ & $50.75 \pm 5.9$ \\
\hline NA & $0 \pm 9.1$ & $-156.83 \pm 14.8$ & $68.87 \pm 18.5$ & $-363.99 \pm 9.1$ & $-520.81 \pm 14.8$ & $-295.12 \pm 18.5$ \\
\hline
\end{tabular}

Table 4. Mean inverted $\mathrm{CO}_{2}$ flux $(\mu)$, error $(\varepsilon)$ in $\mathrm{Tg} \mathrm{C} \mathrm{yr}^{-1}$, and the percentage change $(\Delta \%)$ for global regions from 2002 to 2007.

\begin{tabular}{|c|c|c|c|c|c|c|c|c|c|c|}
\hline \multirow[t]{3}{*}{ Region } & \multicolumn{5}{|c|}{ Experiment 1} & \multicolumn{5}{|c|}{ Experiment 2} \\
\hline & (a) & (b) & & (c) & & (a) & (b) & & (c) & \\
\hline & $\mu \pm \varepsilon$ & $\mu \pm \varepsilon$ & $\Delta \%$ & $\mu \pm \varepsilon$ & $\Delta \%$ & $\mu \pm \varepsilon$ & $\mu \pm \varepsilon$ & $\Delta \%$ & $\mu \pm \varepsilon$ & $\Delta \%$ \\
\hline 18 & $-43.27 \pm 33.1$ & $-38.45 \pm 25.7$ & -11.13 & $-30.41 \pm 28.4$ & -29.71 & $-26.48 \pm 33.1$ & $-18.95 \pm 25.7$ & -28.43 & $-14.74 \pm 28.4$ & -44.32 \\
\hline 19 & $-10.80 \pm 20.3$ & $-17.94 \pm 15.8$ & 66.08 & $-9.49 \pm 17.7$ & -12.07 & $-15.22 \pm 20.3$ & $-17.18 \pm 15.8$ & 12.88 & $-13.41 \pm 17.7$ & -11.87 \\
\hline 20 & $-71.59 \pm 56.9$ & $-271.27 \pm 91.4$ & $278.94^{*}$ & $-223.82 \pm 102.4$ & $212.67^{*}$ & $-113.85 \pm 56.9$ & $-227.33 \pm 91.4$ & $99.67^{*}$ & $-231.71 \pm 102.4$ & $103.52^{*}$ \\
\hline 21 & $-117.07 \pm 59.8$ & $-251.38 \pm 72.7$ & $114.73^{*}$ & $-201.33 \pm 78.3$ & 71.98 & $-132.20 \pm 59.8$ & $-192.76 \pm 72.7$ & 45.81 & $-188.63 \pm 78.3$ & 42.68 \\
\hline 22 & $-104.91 \pm 57.7$ & $-97.89 \pm 46.1$ & -6.69 & $-64.04 \pm 51.9$ & -38.95 & $-145.62 \pm 57.7$ & $-124.70 \pm 46.1$ & -14.36 & $-113.33 \pm 51.9$ & -22.17 \\
\hline 23 & $-0.79 \pm 8.9$ & $-10.69 \pm 7$ & $1257.11^{*}$ & $23.21 \pm 10.2$ & $-3044.92 *$ & $1.66 \pm 8.9$ & $0.34 \pm 7$ & -79.75 & $7.23 \pm 10.2$ & 334.19 \\
\hline 24 & $-0.05 \pm 0$ & $-2.26 \pm 0$ & $4169.81^{*}$ & $6.71 \pm 3.5$ & $-12754.7^{*}$ & $-3.00 \pm 0$ & $-4.93 \pm 0$ & $64.71^{*}$ & $-0.12 \pm 3.5$ & -96.03 \\
\hline 25 & $-7.95 \pm 14.2$ & $-7.69 \pm 10.9$ & -3.29 & $-4.29 \pm 14.2$ & -45.94 & $-23.48 \pm 14.2$ & $-26.09 \pm 10.9$ & 11.12 & $-19.70 \pm 14.2$ & -16.1 \\
\hline 26 & $-92.88 \pm 59.8$ & $-79.49 \pm 47.5$ & -14.42 & $-36.65 \pm 63.8$ & -60.54 & $-160.95 \pm 59.8$ & $-138.33 \pm 47.5$ & -14.06 & $-113.01 \pm 63.8$ & -29.79 \\
\hline 27 & $-111.07 \pm 78.7$ & $-76.22 \pm 64.6$ & -31.38 & $-63.91 \pm 82.9$ & -42.46 & $-175.18 \pm 78.7$ & $-167.96 \pm 64.6$ & -4.12 & $-141.68 \pm 82.9$ & -19.12 \\
\hline 28 & $-69.17 \pm 67.5$ & $-52.21 \pm 51$ & -24.52 & $-16.86 \pm 64.5$ & -75.68 & $-76.25 \pm 67.5$ & $-63.05 \pm 51$ & -17.3 & $-38.29 \pm 64.5$ & -49.78 \\
\hline West & $-62.85 \pm 39.1$ & $-77.03 \pm 30.4$ & 22.55 & $-14.29 \pm 32.7$ & $-77.26^{*}$ & $-66.50 \pm 40.2$ & $-66.81 \pm 20.6$ & 0.46 & $-40.75 \pm 23.4$ & $-38.73^{*}$ \\
\hline Midwest & $-188.65 \pm 80.7$ & $-522.65 \pm 116.8$ & $177.04^{*}$ & $-425.15 \pm 128.8$ & $125.36^{*}$ & $-246.05 \pm 82.3$ & $-420.09 \pm 115.5$ & $70.73^{*}$ & $-420.33 \pm 128.2$ & $70.83^{*}$ \\
\hline Northeast & $-104.91 \pm 57.7$ & $-97.89 \pm 46.1$ & -6.69 & $-64.04 \pm 51.9$ & -38.95 & $-145.62 \pm 57.7$ & $-124.70 \pm 46.1$ & -14.36 & $-131.31 \pm 51.9$ & -9.82 \\
\hline Southeast & $-273.13 \pm 118.2$ & $-207.92 \pm 94.2$ & -23.87 & $-117.42 \pm 119.3$ & -57.01 & $-412.38 \pm 115.5$ & $-369.34 \pm 93.1$ & -10.44 & $-292.98 \pm 119.4$ & -28.95 \\
\hline US & $-629.54 \pm 157.7$ & $-905.48 \pm 153.9$ & 43.83 & $-620.91 \pm 172.7$ & -1.37 & $-870.55 \pm 156.3$ & $-980.94 \pm 152.2$ & 12.68 & $-885.37 \pm 182.4$ & 1.7 \\
\hline Canada & $-295.59 \pm 142.8$ & $-340.58 \pm 139.5$ & -15.22 & $-259.87 \pm 139.7$ & -12.08 & $-255.50 \pm 137.2$ & $-219.74 \pm 136.7$ & -14 & $-217.45 \pm 136.3$ & -14.89 \\
\hline NA & $-932.61 \pm 205.9$ & $-1222.9 \pm 195.9$ & 31.12 & $-883.58 \pm 211.4$ & -5.26 & $-1139.67 \pm 189.9$ & $-1206.04 \pm 181.8$ & 5.82 & $-1110.17 \pm 200.3$ & -2.59 \\
\hline
\end{tabular}

* Represents regions with SNR > 1, and positive percentage change in $\Delta \%$ represents increase in uptake. West includes regions 18, 19, 23, 24, and 25; Midwest includes regions 20 and 21; northeast includes region 22; and southeast includes regions 26, 27, and 28.

the atmospheric $\mathrm{CO}_{2}$ measurements are able to differentiate about two-third of the differences in fluxes among the regions and the inverted flux is highly sensitive to the prior flux.

Even though the nested regions in North America are fairly large, the atmospheric signal from the $\mathrm{CO}_{2}$ observation network is blurred substantially among the regions due to efficient atmospheric mixing. Schuh et al. (2010) conducted a high-resolution inversion over North America and found that the inverted flux spatial distribution in $40 \mathrm{~km}$ grids differs greatly from that of CarbonTracker because the prior fluxes used in their system and CT are quite different. The highresolution posterior maps of the carbon source and sink distributions from these two systems resemble closely the spatial details in the prior maps, demonstrating that the atmosphere measurements could only adjust the broad spatial patterns but not the spatial details in the inversion process. In their study, a decorrelation distance of $600 \mathrm{~km}$ was judged to be suitable to produce the posterior flux distribution, meaning that the ability of the atmospheric measurements to differentiate flux spatial patterns deteriorates greatly at spatial 

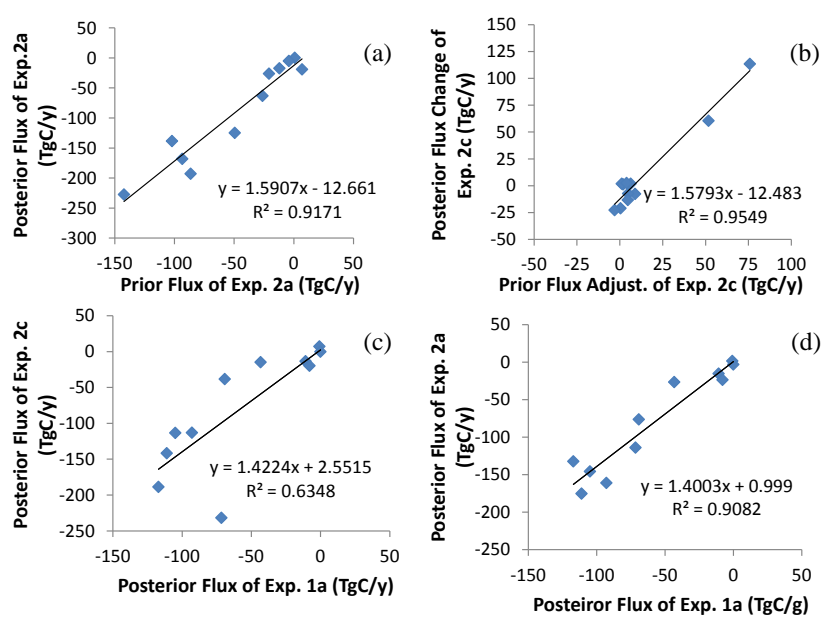

Figure 5. Dependence of the posterior flux from inversions on the prior flux for regions 18-28. (a) Correlation between posterior fluxes from experiment $2 \mathrm{a}$ and their prior fluxes, (b) correlation between changes in posterior fluxes from experiment $2 \mathrm{c}$ and adjustments to their prior fluxes, (c) correlation of the posterior fluxes between experiment 1a and experiment $2 \mathrm{c}$, and (d) correlation of the posterior fluxes between experiment $1 \mathrm{a}$ and experiment $2 \mathrm{a}$.

scales smaller than $600 \mathrm{~km}$. Our nested region size is about the same as this decorrelation distance, and therefore our inverted regional fluxes do not lose much spatial information contained in the atmospheric measurements.

The result of experiment $2 \mathrm{a}$ for region 20 is comparable to the sink of $0.11 \mathrm{Pg} \mathrm{C} \mathrm{yr}^{-1}$ for cropland in about the same region from 2001 to 2005 reported by Peters et al. (2007), in which the biospheric flux was not adjusted for crop production and consumption. The comparison suggests that both sets of inversions captured about the same strength of the atmospheric sink signal in this region. After crop adjustments in experiment $2 \mathrm{c}$, the sink magnitude in region 20 is approximately doubled with a total of $0.23 \mathrm{Pg} \mathrm{C} \mathrm{yr}^{-1}$ (Table 4) or $298 \mathrm{~g} \mathrm{C} \mathrm{m}^{-2} \mathrm{yr}^{-1}$. The corresponding sink magnitude in region 21 is $0.19 \mathrm{PgC} \mathrm{yr}^{-1}$ or $181 \mathrm{~g} \mathrm{C} \mathrm{m}^{-2} \mathrm{yr}^{-1}$. In the Mid-Continent Intensive (MCI) study (Schuh et al., 2013), three inversion models produced an average sink of about $0.15 \mathrm{Pg} \mathrm{Cyr}^{-1}$ or $150 \mathrm{~g} \mathrm{C} \mathrm{m}^{-2} \mathrm{yr}^{-1}$. This result is comparable to the value of $0.183 \mathrm{PgC} \mathrm{yr}^{-1}$ or $183 \mathrm{~g} \mathrm{C} \mathrm{m}^{-2} \mathrm{yr}^{-1}$ produced in another inversion study (Lauvaux et al., 2012) for the same MCI area over a growing season from June to December (the dormant season in other months presumably has small fluxes). The MCI study area of $1000 \mathrm{~km} \times 1000 \mathrm{~km}$ covers $52 \%$ of regions 20 and 21 , with areas of 1275 and $631 \mathrm{~km}^{2}$, respectively. The area-weighted flux density of these two regions is $219 \mathrm{~g} \mathrm{C} \mathrm{m}^{-2} \mathrm{yr}^{-1}$, which is about $15-$ $40 \%$ larger than previous inversion results from Schuh et al. (2013) and Lauvaux et al. (2012). The difference of our inversion results from these MCI studies is within the posterior uncertainty of our inversion, but it also indicates the need for further evaluation of our inversion results. In these regions, the major crops are corn and soybean. Using eddy covariance systems at three local sites in region 20, Verma et al. (2005) measured NEP of irrigated corn, irrigated corn-soybean rotation, and rainfed corn-soybean rotation in 2001-2004 to be 441, 351, and $296 \mathrm{~g} \mathrm{C} \mathrm{m}^{-2} \mathrm{yr}^{-1}$, respectively. The inverted sink per unit land area is much smaller than these site-level sink values because productive crops only occupy about $50 \%$ of the area in these regions.

Table 4 also provides aggregated results for four large US census regions - west, Midwest, northeast, and southeast - as well as the US and Canada. Crop consumption adjustments make significant $(\mathrm{SNR}>1)$ changes to the inverted carbon flux in the west region in both experiments 1 and 2. This is mostly due to the large crop consumption in California. In experiment $2 b$ with the non-neutralized and interannually variable prior biospheric flux, the crop production adjustment alone does not greatly affect the inverted sink in the west region, but it does significantly increase the sink in the Midwest region with high crop production. Similar to experiment 1 , the total sinks in North America and Canada from experiment 2 show large changes in sink sizes after the production adjustment. This suggests that in atmospheric inversion estimates the changes in the a priori flux affect the inverted results not only locally but also globally (Gurney et al., 2004). The overall US and North American carbon sinks are similar to the control case when the crop consumption adjustment is also made (experiments $2 \mathrm{~b}$ ), where the percentage changes are only 1.7 and $-2.6 \%$ (Table 3 ), respectively. This result reinforces our original assumption that the long-term cropland carbon budget is approximately balanced between the crop production and consumption (West et al., 2011).

\subsubsection{Multi-year global carbon budget}

Although the cropland carbon adjustments were only made for the US regions, the $\mathrm{CO}_{2}$ flux is inverted globally using the nested inversion system, which not only avoids the need to set up boundary conditions for North America but also produces results for other regions for comprehensive analysis. Table 6 provides the average annual inverted $\mathrm{CO}_{2}$ fluxes globally from 2002 to 2007 for experiments 1 and 2 . It also summarizes the mean inverted $\mathrm{CO}_{2}$ fluxes $(\mu)$ and errors $(\varepsilon)$, as well as percentage changes $(\Delta \%)$ from the control case for the large regions outside of North America. In the results for both experiments 1 and 2, agricultural adjustments affect the two North America regions (NA-S and NA-N) similarly, indicating that these two regions are closely linked as many $\mathrm{CO}_{2}$ stations within and around North America are affected by fluxes from both regions. With the crop adjustments, changes in the inverted flux are observed in many regions outside the US, although no adjustments to the prior flux were made outside of the US. A plausible explanation for these results is that any changes in the total sinks in the conterminous US must be compensated for by other regions around the globe since the global carbon 
Table 5. Correlation coefficients of the change in the inverted flux from experiments $2 \mathrm{a}$ to that of experiment $2 \mathrm{c}$ among 11 regions in the US, calculated based on inverted annual fluxes in 2000-2007.

\begin{tabular}{lrrrrrrrrrrr}
\hline Region & 18 & 19 & 20 & 21 & 22 & 23 & 24 & 25 & 26 & 27 & 28 \\
\hline 18 & 1 & 0.88 & -0.57 & -0.56 & 0.33 & 0.13 & -0.16 & 0.55 & 0.09 & 0.16 & 0.75 \\
19 & 0.88 & 1 & -0.54 & -0.69 & 0.43 & 0.29 & 0.02 & 0.72 & 0.17 & 0.16 & 0.70 \\
20 & -0.57 & -0.54 & 1 & 0.06 & -0.36 & -0.34 & 0.12 & -0.01 & -0.46 & -0.21 & -0.19 \\
21 & -0.56 & -0.69 & 0.06 & 1 & -0.48 & 0.10 & 0.10 & -0.78 & -0.44 & -0.25 & -0.71 \\
22 & 0.33 & 0.43 & -0.36 & -0.48 & 1 & -0.18 & -0.45 & 0.12 & 0.61 & 0.09 & -0.01 \\
23 & 0.13 & 0.29 & -0.34 & 0.10 & -0.18 & 1 & 0.87 & 0.41 & -0.14 & 0.67 & 0.23 \\
24 & -0.16 & 0.02 & 0.12 & 0.10 & -0.45 & 0.87 & 1 & 0.41 & -0.27 & 0.63 & 0.16 \\
25 & 0.55 & 0.72 & -0.01 & -0.78 & 0.12 & 0.41 & 0.41 & 1 & -0.03 & 0.46 & 0.86 \\
26 & 0.09 & 0.17 & -0.46 & -0.44 & 0.61 & -0.14 & -0.27 & -0.03 & 1 & 0.29 & -0.03 \\
27 & 0.16 & 0.16 & -0.21 & -0.25 & 0.09 & 0.67 & 0.63 & 0.46 & 0.29 & 1 & 0.37 \\
28 & 0.75 & 0.70 & -0.19 & -0.71 & -0.01 & 0.23 & 0.16 & 0.86 & -0.03 & 0.37 & 1 \\
\hline
\end{tabular}

budget is constrained by mean changes in the atmospheric $\mathrm{CO}_{2}$ concentration. In an atmospheric inversion study, Gurney et al. (2004) found that contributions from land fluxes appeared in the adjacent ocean regions, and they described this phenomenon as flux "leakage". In our case, the compensating effect seen in other regions outside of the conterminous US may also be considered as a leakage. This leakage puts into question the reliability of the atmospheric $\mathrm{CO}_{2}$ measurements in optimizing the local flux if the prior information is biased, given the fact that North America is one of the continents with strong data constraints. We would therefore expect that similar adjustments in other regions of the globe with fewer observation stations can cause larger flux leakages toward regions with weaker atmospheric constraints.

The inverted total global land sink from experiment 2 is larger than that from experiment 1 (Table 5) because the prior land sink in experiment 2 is larger than that in experiment 1. To compensate for this influence of the prior flux over land, the inverted ocean sink is smaller in experiment 2 than in experiment 1 . The total land and ocean sinks do not show large changes with the crop production or crop consumption adjustments in the US in both experiments (Table 5). Relative to experiment 1 , experiment 2 shows a slightly larger decrease in the terrestrial sink and a slightly larger increase in the ocean sink. The overall crop adjustments allocate a slightly smaller sink to North America, while most regions outside of North America adjust accordingly to balance the global carbon budget due to weak data constraints in other regions.

\subsubsection{Seasonal variation}

The timing of the $\mathrm{CO}_{2}$ uptake and release from croplands exerts great influences on the atmospheric $\mathrm{CO}_{2}$ (Corbin et al., 2010), as crops in different regions differ in their growth patterns. The seasonal variation pattern in the surface flux may coincide with that in the strength of atmospheric boundary layer mixing, causing the rectifier effect on atmospheric transport (Denning et al., 1995; Gurney, 2004). In this research, the a priori seasonal variation for cropland is based on BEPS, which considers the seasonal variations in vegetation structure using remotely sensed LAI and meteorology. Figure 6 shows the monthly a priori and a posteriori $\mathrm{CO}_{2}$ fluxes for the period of 2002-2007 from experiment 2 for regions of high crop production and high crop consumption in the US. Results from experiment 1 are not shown, but they are similar in the seasonal variation pattern.

In regions 20 and 21 of high crop production, the inverted monthly fluxes with agricultural adjustments show higher uptake during the peak growing season of June, July, and August and a stronger release of carbon during the non-growing season in October and November than the prior fluxes. March and April show a net uptake in the $\mathrm{CO}_{2}$ inverted fluxes in agriculturally adjusted experiments in region 20 instead of near carbon neutrality shown in the control experiment. In regions 23 and 24 of high crop consumption with low vegetation, the impacts of crop consumption adjustment are mostly shown as persistent decreases in sinks throughout the year, while those with the production adjustment have persistent increases. In the US southeast, a region with mixed forests and moderate crop production and consumption (regions 26, 27,28 ), the crop production adjustment (experiment $2 b$ ) and the crop production and consumption adjustments (experiment 2c) cause discernible to considerable impacts on the magnitude of the $\mathrm{CO}_{2}$ uptake during the growing season and release during non-growing seasons.

The changes in the monthly inverted fluxes after adjusting for crop production and consumption are mainly observed as changes in the magnitude instead of the timing of the growing seasons. This means that the seasonal pattern of the inverted $\mathrm{CO}_{2}$ flux generally follows that of the a priori flux. In making our US cropland carbon adjustments, annual cropland census data are used instead of actual cropland seasonal variations, while the seasonal growth pattern is modeled based on remotely sensed LAI and meteorology. Therefore, these results are constrained by remote sensing 

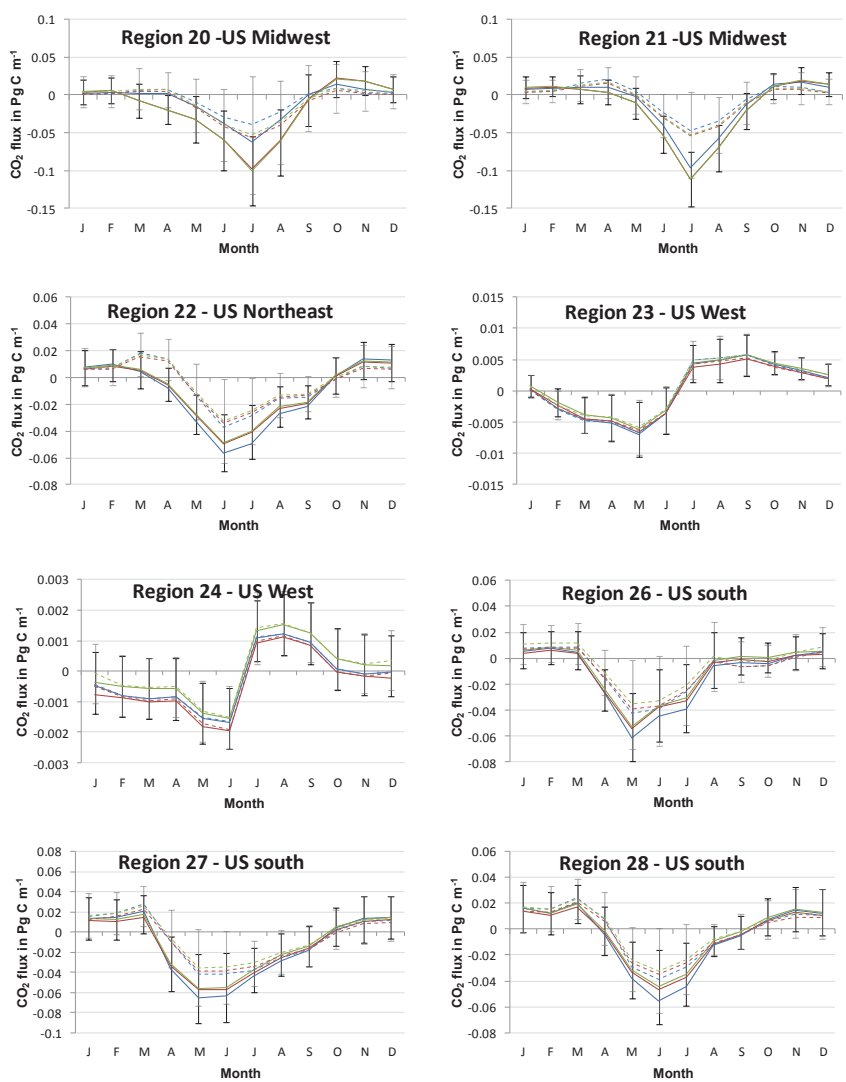

Figure 6. Monthly inverted (solid lines) and prior (dashed lines) $\mathrm{CO}_{2}$ flux (negative values are sinks) averaged over 2002 to 2007 for Experiments 2 - annually varying terrestrial prior fluxes with (a) no adjustments - blue; (b) production adjustments - red; (c) crop production and consumption adjustments - green.

information, although they are also subject to certain uncertainties due to errors in retrieved LAI and the model.

\subsection{Discussion}

After integrating US crop production and consumption data into the prior flux, the US Midwest becomes a large regional $\mathrm{CO}_{2}$ sink from 2002 to 2007 in our inverse modeling. This is mainly due to the large uptake of $\mathrm{CO}_{2}$ during the growing season (Peters et al., 2007). Because of the release of the $\mathrm{CO}_{2}$ in regions of sizable crop consumption by humans and livestock, a weakening of the US southeast forest sink is found in our inversion. With the neutralization of the annual prior flux before adjusting for crop consumption (experiment 1), the US Midwest is perceived by the "atmospheric view" as the dominant sink in North America. While croplands in the US Midwest uptake large amounts of carbon during the growing season, some of this carbon is decomposed on-site, while the remainder is transported off-site and respired back to the atmosphere elsewhere. Therefore, lateral transport of carbon needs to be considered in order to reconcile atmospheric inversion results with ground-based mea- surements (Hayes et al., 2012; Gourdji et al., 2012). On the west coast, including California, where there are high levels of human and livestock consumption, an overall $\mathrm{CO}_{2}$ source is obtained from the inversion. With the incorporation of US cropland carbon data, the main US sink is redistributed from the US southeast and west forested regions to the US Midwest cropland in the inversion process. In order to assess the possible range of errors in our inversion system, this redistribution is shown in the results from two sets of experiments. Experiment 1, which gives larger weights to the influence of atmospheric $\mathrm{CO}_{2}$ observation than to the prior terrestrial flux, shows the sink in the US Midwest to be larger than that in the US southeast. Similar results are also obtained in experiment 2, which gives larger weights to the prior terrestrial flux as an opposite case. In both experiments, the inclusion of agricultural inventory data in the priors significantly altered the inversion results for several regions in the west and Midwest regions. Although the atmospheric $\mathrm{CO}_{2}$ measurements contain much information on the spatial distribution of the carbon sink over the continent, our analysis reveals that they are insufficient for differentiating large flux differences among productive and non-productive regions (Fig. 5). The inverted flux distribution is mostly determined by the prior distribution. This point may be no better demonstrated than the MCI study of Schuh et al. (2013), in which three inversion studies show different inversion results but all closely resemble the prior distributions, although there are $16 \mathrm{CO}_{2}$ observation sites within the MCI study region.

In experiment 1 , based on an annually neutralized prior ecosystem flux, the overall magnitudes of the US and North American sinks are weakened by $\sim 1.4$ and $\sim 5.3 \%$ after the cropland production and consumption adjustments are made, respectively. Furthermore, regions outside of the US are also affected by these adjustments, and the Canadian carbon sink shows noticeable weakening $(12.1 \%)$ (Table 4). Many regions outside of North America, which are not as well constrained by $\mathrm{CO}_{2}$ observations, also show small changes when these adjustments are made (Table 6). While these changes may have been affected by the additional errors introduced to the uncertainty matrix of the prior flux, the leakage of the $\mathrm{CO}_{2}$ flux from the adjusted regions into other regions with poor constraints may be the main reason for these changes (Gurney et al., 2004). While not conclusive, this phenomenon of leakage points to the importance of the prior flux for constraining atmospheric inversion for the carbon flux of small regions with sparse atmospheric $\mathrm{CO}_{2}$ measurements. Since the unneutralized flux is closer to reality than the neutralized flux in terms of the annual sink magnitude, the following further discussion is therefore based on results from experiment 2.

During the period from 2002 to 2007, the annual mean crop production and consumption over the conterminous US based on West et al. (2011) were $\sim 0.27$ and $\sim 0.24 \mathrm{Pg} \mathrm{Cyr}^{-1}$, respectively. The consumption is smaller than production by about $0.03 \mathrm{Pg} \mathrm{Cyr}^{-1}$, which is close to 
Table 6. Mean inverted $\mathrm{CO}_{2}$ flux $(\mu)$, error $(\varepsilon)$ in $\mathrm{Pg} \mathrm{Cyr}^{-1}$, and the percentage change $(\Delta \%)$ for global regions from 2002 to 2007.

\begin{tabular}{|c|c|c|c|c|c|c|c|c|c|c|}
\hline \multirow[t]{3}{*}{ Region } & \multicolumn{5}{|c|}{ Experiment 1} & \multicolumn{5}{|c|}{ Experiment 2} \\
\hline & (a) & (b) & & (c) & & (a) & (b) & & (c) & \\
\hline & $\mu \pm \varepsilon$ & $\mu \pm \varepsilon$ & $\Delta \%$ & $\mu \pm \varepsilon$ & $\Delta \%$ & $\mu \pm \varepsilon$ & $\mu \pm \varepsilon$ & $\Delta \%$ & $\mu \pm \varepsilon$ & $\Delta \%$ \\
\hline NA-N & $0.28 \pm 0.14$ & $0.24 \pm 0.14$ & -13.01 & $-0.26 \pm 0.14$ & -7.57 & $-0.22 \pm 0.14$ & $-0.18 \pm 0.14$ & -14.89 & $-0.20 \pm 0.14$ & -7.83 \\
\hline NA-S & $.65 \pm 0.16$ & $0.74 \pm 0.16$ & 14.07 & $-0.63 \pm 0.16$ & -2.95 & $-0.92 \pm 0.16$ & $-1.02 \pm 0.16$ & 10.65 & $-0.91 \pm 0.19$ & -1.37 \\
\hline 31 & $0.36 \pm 0.41$ & $0.35 \pm 0.41$ & -0.61 & $0.34 \pm 0.41$ & -5.59 & $0.34 \pm 0.41$ & $0.39 \pm 0.41$ & 14.34 & $0.37 \pm 0.41$ & 9.12 \\
\hline 32 & $-0.07 \pm 0.27$ & $-0.07 \pm 0.27$ & -3.62 & $-0.06 \pm 0.27$ & -10.04 & $-0.11 \pm 0.27$ & $-0.09 \pm 0.27$ & -16.89 & $-0.08 \pm 0.27$ & -21.02 \\
\hline 33 & $-0.20 \pm 0.28$ & $-0.19 \pm 0.28$ & -5.45 & $-0.22 \pm 0.28$ & 8.30 & $-0.28 \pm 0.28$ & $-0.19 \pm 0.28$ & -33.92 & $-0.22 \pm 0.28$ & -24.07 \\
\hline 34 & $-0.86 \pm 0.27$ & $-0.86 \pm 0.27$ & -0.15 & $-0.86 \pm 0.27$ & -0.63 & $-0.93 \pm 0.27$ & $-0.91 \pm 0.27$ & -2.33 & $-0.91 \pm 0.27$ & -2.78 \\
\hline 35 & $-0.90 \pm 0.26$ & $-0.87 \pm 0.26$ & -2.97 & $-0.89 \pm 0.26$ & -0.40 & $-1.00 \pm 0.26$ & $-0.96 \pm 0.26$ & -3.73 & $-0.99 \pm 0.26$ & -1.42 \\
\hline 36 & $-0.63 \pm 0.24$ & $-0.61 \pm 0.24$ & -3.34 & $-0.64 \pm 0.24$ & 0.57 & $-0.52 \pm 0.24$ & $-0.54 \pm 0.24$ & 4.97 & $-0.57 \pm 0.24$ & 9.75 \\
\hline 37 & $-0.54 \pm 0.24$ & $-0.54 \pm 0.24$ & 0.57 & $-0.54 \pm 0.24$ & 0.78 & $-0.63 \pm 0.24$ & $-0.59 \pm 0.24$ & -7.49 & $-0.59 \pm 0.24$ & -7.32 \\
\hline 38 & $0.06 \pm 0.08$ & $0.06 \pm 0.08$ & 1.05 & $0.06 \pm 0.08$ & 1.91 & $0.04 \pm 0.08$ & $0.04 \pm 0.08$ & -2.77 & $0.04 \pm 0.08$ & -1.58 \\
\hline 39 & $-0.21 \pm 0.21$ & $-0.18 \pm 0.21$ & -14.44 & $-0.19 \pm 0.21$ & -7.45 & $-0.06 \pm 0.21$ & $-0.01 \pm 0.21$ & -88.22 & $-0.02 \pm 0.21$ & -64.84 \\
\hline 40 & $-0.58 \pm 0.15$ & $-0.58 \pm 0.15$ & 1.22 & $-0.59 \pm 0.15$ & 3.00 & $-0.62 \pm 0.15$ & $-0.63 \pm 0.15$ & 1.22 & $-0.64 \pm 0.15$ & 2.87 \\
\hline 41 & $-0.06 \pm 0.12$ & $-0.07 \pm 0.12$ & 10.86 & $-0.06 \pm 0.12$ & 2.11 & $0.00 \pm 0.12$ & $-0.01 \pm 0.12$ & 138.30 & $0.00 \pm 0.12$ & -45.39 \\
\hline 42 & $0.74 \pm 0.14$ & $0.74 \pm 0.14$ & -0.72 & $0.74 \pm 0.14$ & -0.14 & $0.80 \pm 0.14$ & $0.79 \pm 0.14$ & -0.90 & $0.79 \pm 0.14$ & -0.36 \\
\hline 43 & $-0.58 \pm 0.18$ & $-0.58 \pm 0.18$ & & $-0.58 \pm 0.18$ & -0.35 & $-0.51 \pm 0.18$ & $-0.51 \pm 0.18$ & 0.77 & $-0.51 \pm 0$ & 0.08 \\
\hline 44 & $-0.27 \pm 0.07$ & $-0.28 \pm 0.07$ & 2.85 & $-0.27 \pm 0.07$ & 1.07 & $-0.27 \pm 0.07$ & $-0.28 \pm 0.07$ & 3.52 & $-0.28 \pm 0.07$ & 1.76 \\
\hline 45 & $-0.34 \pm 0.12$ & $-0.34 \pm 0.12$ & -0.84 & $-0.36 \pm 0.12$ & 4.30 & $-0.31 \pm 0.12$ & $-0.30 \pm 0.12$ & -3.08 & $-0.32 \pm 0.12$ & 2.52 \\
\hline 46 & $0.10 \pm 0.12$ & $0.10 \pm 0.12$ & -0.60 & $0.10 \pm 0.12$ & -0.41 & $0.15 \pm 0.12$ & $0.15 \pm 0.12$ & 1.02 & $0.15 \pm 0.12$ & 1.14 \\
\hline 47 & $-0.32 \pm 0.14$ & $-0.32 \pm 0.14$ & -1.28 & $-0.32 \pm 0.14$ & -1.52 & $-0.33 \pm 0.14$ & $-0.33 \pm 0.14$ & -0.94 & $-0.33 \pm 0.14$ & -1.18 \\
\hline 48 & $0.15 \pm 0.06$ & $0.15 \pm 0.06$ & -1.04 & $0.15 \pm 0.06$ & -0.77 & $0.14 \pm 0.06$ & $0.14 \pm 0.06$ & -0.73 & $0.14 \pm 0.06$ & -0.45 \\
\hline 49 & $0.06 \pm 0.16$ & $0.05 \pm 0.16$ & -6.59 & $0.06 \pm 0.16$ & -2.21 & $0.14 \pm 0.16$ & $0.14 \pm 0.16$ & 2.54 & $0.15 \pm 0.16$ & 4.36 \\
\hline 50 & $-0.56 \pm 0.13$ & $-0.56 \pm 0.13$ & -0.64 & $-0.56 \pm 0.13$ & -0.87 & $-0.53 \pm 0.13$ & $-0.53 \pm 0.13$ & -0.42 & $-0.53 \pm 0.13$ & -0.66 \\
\hline Land & $-3.93 \pm 0.67$ & $-3.89 \pm 0.67$ & -0.83 & $-3.90 \pm 0.65$ & -0.72 & $-4.30 \pm 0.66$ & $-4.07 \pm 0.65$ & -5.39 & $-4.07 \pm 0.66$ & -5.29 \\
\hline Oceans & $-1.67 \pm 0.37$ & $-1.69 \pm 0.37$ & 1.43 & $-1.70 \pm 0.37$ & 1.70 & $-1.37 \pm 0.38$ & $-1.38 \pm 0.37$ & 0.98 & $-1.39 \pm 0.37$ & 1.31 \\
\hline Total & $-5.59 \pm 0.75$ & $-5.59 \pm 0.75$ & -0.16 & $-5.59 \pm 0.74$ & 0.01 & $-5.66 \pm 0.75$ & $-5.45 \pm 0.74$ & -3.85 & $-5.46 \pm 0.75$ & -3.70 \\
\hline
\end{tabular}

* represents regions with SNR $>1$, and positive percentage change in $\Delta \%$ represents increase in uptake/release.

the value of $0.047 \mathrm{Pg} \mathrm{C} \mathrm{yr}^{-1}$ for the net US agricultural carbon export in 2008 estimated by West et al. (2011). For the US Midwest, the inverted results with agricultural adjustments show a large sink of $0.42 \pm 0.13 \mathrm{Pg} \mathrm{Cyr}^{-1}$ (experiment 2c). The value is reduced to $0.24 \mathrm{Pg} \mathrm{C} \mathrm{yr}^{-1}$ if these adjustments are not made (experiment 2a). These adjustments make a difference of approximately $67 \%$ of the total annual crop production in the US. This suggests that the NEP simulations from the Boreal Ecosystem Productivity Simulator underestimate the processes that relate to cropland $\mathrm{CO}_{2}$ sinks because it assumes the consumption (respiration) occurs at the same location as production.

The US west and southeast, being regions of large population and crop consumption, show a combined $0.145 \mathrm{Pg} \mathrm{C} \mathrm{yr}^{-1}$ weakening of the sink after the crop adjustments (experiment 2c). This sink reduction is about $60 \%$ of the total annual crop consumption averaged over 2002 to 2007 ( $\sim 24 \mathrm{Pg} \mathrm{Cyr}^{-1}$, based on West et al., 2011), indicating the importance of using the crop consumption data for these two regions in the inversion.

Using an atmospheric inversion technique over North America, Peters et al. (2007) showed the US Midwest to be the major sink and the US southeast forest region to be either carbon-neutral or a source between 2002 and 2007. In our inversion constrained by the annually neutralized a priori flux adjusted for crop production and consumption (experiment 1c, Table 4), the US Midwest is also shown to be a large $\mathrm{CO}_{2}$ sink, but the US southeast forest region remains a sizable carbon sink of $0.117 \pm 0.12 \mathrm{PgC} \mathrm{yr}^{-1}$ in the same period. Our result differs from that of Peters et al. (2007) for the US southeast, mostly because of different prior fluxes used. Our inversion with the unneutralized prior flux modeled by BEPS (experiment 2a) produced a large sink of $0.413 \pm 0.12{\mathrm{PgC} y r^{-1}}$ for the southeast (Table 4), and, with crop production and consumption adjustments to the unneutralized prior flux (experiment 2c), the southeast still remains a strong sink of $0.293 \pm 0.12 \mathrm{Pg} \mathrm{C} \mathrm{yr}^{-1}$. From the neutralized experiments, we can infer that the atmospheric signal is forcing the inversion in the sink direction for the US southeast. Although the sink is reduced by $42 \%$ when crop production and consumption in this region are considered, this atmospheric signal seems to be robust in indicating this region to be a large sink. The results from experiment 2 show that this sink signal is considerably strengthened if the prior flux is a sink, as we would expect from bottom-up modeling (Zhang et al., 2012) for forests considering the predominant mid-age forest structure (Pan et al., 2011b). The effect of the crop consumption adjustment taken as the difference between experiments $2 b$ and $2 c$ give us confidence that the 
crop consumption in the US southeast is not large enough to offset the forest sink in this region.

The main components of the US cropland carbon budget presented by West et al. (2011) are the crop production and consumption. However, there is also a non-negligible portion of the crop products being exported outside of the US. Ciais et al. (2007) showed the importance of this lateral transport of carbon internationally. In our study, the lateral international transport of crop carbon is not considered, but its effects on the US carbon cycle might have been included to the first order by the difference between crop production of $\sim 0.27 \mathrm{Pg} \mathrm{C} \mathrm{yr}^{-1}$ and crop consumption of $\sim 0.24 \mathrm{Pg} \mathrm{C} \mathrm{yr}^{-1}$ within the USA. This small imbalance has equivalent effects on the distribution of carbon sinks between Canada and the US, and among continents.

While the use of census-based cropland carbon data is cautioned due to their potentially large uncertainties (Chan and Lin, 2011), our research shows that agricultural statistical data give valuable information on the spatial patterns and the magnitude of the surface $\mathrm{CO}_{2}$ flux. Cropland carbon and atmospheric $\mathrm{CO}_{2}$ data, when used in combination, are shown to be able to optimize the prior terrestrial $\mathrm{CO}_{2}$ flux simulated by a biospheric model and can suggest areas of improvement in the model. This research shows that for managed land cover types such as croplands, where the carbon uptake and release are not simply determined by biospheric processes, biospheric models should not be the only tool used for generating prior terrestrial surface $\mathrm{CO}_{2}$ fluxes (Ciais et al., 2007). Inventory data, such as agricultural statistics, are shown in this research to provide the missing spatial information useful for regional carbon budget estimation using atmospheric inversion techniques. Since the atmospheric mixing is efficient and $\mathrm{CO}_{2}$ concentration measurements are sparse, we rely on an accurate prior to obtain a reliable estimate of the regional carbon sink and source distribution.

\section{Conclusions}

Through adjusting the prior terrestrial carbon flux from a biospheric model using crop production and consumption data at the county level over the conterminous US, we conducted two sets of atmospheric inversion experiments for the purpose of investigating the influence of the crop data on the spatial distribution of inverted carbon flux over North America from 2002 to 2007. One set of experiments utilizes the prior flux that is annually neutralized for each region before the adjustments, and the other set utilizes the prior flux without the neutralization. These two sets of experiments allow us to explore the strength of the atmospheric signal on the carbon source and sink distribution and the possible ranges of the influences of crop data on the inverted carbon flux. The main findings of this research are summarized as follows.

1. The spatial distribution of the inverted carbon flux among 30 regions in North America is sensitive to changes in the prior flux after the crop production and consumption adjustments. Similar to many other biospheric models, the model used in this study provides a prior carbon flux without considering the lateral transport of carbon and therefore does not capture the large consumption sources and underestimates the large production sinks. With the annually neutralized prior, atmospheric $\mathrm{CO}_{2}$ measurements detected strong sink signals in crop production regions but not the weak source signals in crop consumption regions. While we agree with Gurney et al. (2003), who suggested that inverted fluxes are insensitive to small changes in the a priori fluxes for regions well constrained by atmospheric data, our results show that lateral carbon transport adjustments to the a priori flux are large enough to significantly alter the spatial distribution of the inverted flux. In some crop production and consumption regions, changes in the inverted flux are larger than the uncertainty estimate. Although West et al. (2011) showed the annual cropland carbon budget to be approximately balanced over the conterminous US, the spatial distributions of crop production and consumption are highly uneven, and it would be useful to integrate this information into the prior flux in atmospheric inversion systems. We therefore agree with the suggestion of Ciais et al. (2007) that simply forcing the prior fluxes in inversions to follow spatial patterns of NPP is not compatible with regional patterns of $\mathrm{CO}_{2}$ sources and sinks due to crop product displacement.

2. Integration of crop data in the prior fluxes has helped identify some robust atmospheric signals in some source and sink regions. Similar to Peters et al. (2007), we also find the US Midwest to be a large $\mathrm{CO}_{2}$ sink due to crop production, whether or not the production and consumption adjustments are made or the prior flux is neutralized. Dissimilar to Peters et al. (2007), we find the forest regions in the US southeast to be a considerable sink. The neutralization of the prior flux and the adjustments for crop consumption make the sink smaller, but these regions remain sizable sinks throughout the inversion period from 2002 to 2007 . This robust signal confirms the finding of Zhang et al. (2012) that the US southeast is a large sink because of the large fraction of mid-age, actively growing forests. The usage of the crop data has helped reconcile top-down and bottom-up results, in agreement with Hayes et al. (2012).

3. The crop adjustments made to the prior carbon flux over the conterminous US also altered the inverted flux outside the US when the biospheric flux was neutralized on an annual basis. This seems to be a leakage of the flux to regions outside of the adjusted regions, a similar case to that previously found by Gurney et al. (2004). Without sufficient atmospheric $\mathrm{CO}_{2}$ data to constrain each region, the alteration of the flux in one region 
is mostly compensated for by other regions, especially those in the vicinity and that are least constrained. This result confirms that our current ground-based $\mathrm{CO}_{2}$ observation network is not dense enough in any region in the world to conduct inversions without the additional prior flux constraint. Therefore, more attention should be given to obtaining accurate prior fluxes for inversion purposes or greatly expanding the current $\mathrm{CO}_{2}$ observation network.

Acknowledgements. This research is supported by a research grant (2010CB950704) under the Global Change Program of the Chinese Ministry of Science and Technology, an individual grant (GR-646) from the previous Canadian Foundation of Climate and Atmospheric Sciences (CFCAS), and a Canada Research Chair program.

Edited by: A. Michalak

\section{References}

Aumont, O.: An ecosystem model of the global ocean including $\mathrm{Fe}, \mathrm{Si}, \mathrm{P}$ colimitations, Global Biogeochem. Cy., 17, doi:10.1029/2001GB001745, 2003.

Baker, D., Law, R. M., Gurney, K. R., Rayner, P. J., Peylin, P., Denning, A. S., Bousquet, P., Bruhwiler, L., Chen, Y. H., Ciais, P., Fung, I. Y., Heimann, M., John, J., Maki, T., Maksyutov, S., Masarie, K., Prather, M., Pak, B., Taguchi, S., and Zhu, Z.: TransCom 3 inversion intercomparison: Impact of transport model errors on the interannual variability of regional $\mathrm{CO}_{2}$ fluxes, 1988-2003, Global Biogeochem. Cy., 20, 1988-2003, doi:10.1029/2004GB002439, 2006.

Bolinder, M. A., Janzen, H. H., Gregorich, E. G., Angers, D. A., and VandenBygaart, A. J.: An approach for estimating net primary productivity and annual carbon inputs to soil for common agricultural crops in Canada, Agr. Ecosys. Environ., 18, 29-42, doi:10.1016/j.agee.2006.05.013, 2007.

Buitenhuis, E. T., Le Quéré, C., Aumont, O., Beaugrand, G., Bunker, A., Hirst, A., Ikeda, T., O’Brien, T., Piontkovski, S., and Straile D.: Biogeochemical fluxes through mesozooplankton, Global Biogeochem. Cy., 20, 1-18, doi:10.1029/2005GB002511, 2006.

Canadell, J. G., Le Quéré, C., Raupach, M. R., Field, C. B., Buitenhuis, E. T., Ciais, P., Conway, T. J., Gillett N. P., Houghton R. A., and Marland G.: Contributions to accelerating atmospheric $\mathrm{CO}_{2}$ growth from economic activity, carbon intensity, and efficiency of natural sinks, P. Natl. Acad. Sci. USA, 104, 18866-18870, doi:10.1073/pnas.0702737104, 2007.

CDIAC: Carbon Sources and Sinks Associated with US Cropland Production, US Department of Energy, Carbon Dioxide Information Analysis Center, Oak Ridge, Tennessee, USA, available at: http://cdiac.ornl.gov/carbonmanagement (last access: 12 January 2015), 2014.

Chan, E. C. and Lin, J. C.: What is the value of agricultural census data in carbon cycle studies?, J. Geophys. Res., 116, 1-14, doi:10.1029/2010JG001617, 2011.
Chen, B., Chen, J. M., Mo, G., Yuen, C.-W., Margolis, H., Higuchi, K., and Chan, D.: Modeling and Scaling Coupled Energy, Water, and Carbon Fluxes Based on Remote Sensing: An Application to Canada's Landmass, J. Hydrometeorol., 8, 123-143, doi:10.1175/JHM566.1, 2007.

Chen, J. M., Liu, J., and Cihlar, J.: Daily canopy photosynthesis model through temporal and spatial scaling for remote sensing applications, Ecol. Model., 124, 99-119, doi:10.1016/S03043800(99)00156-8, 1999.

Chen, J. M., Ju, W., Cihlar, J., Price, D., Liu, J., Chen, W., Pan, J., Black, T. A., and Barr, A.: Spatial distribution of carbon sources and sinks in Canada's forests, Tellus, 55, 622-641, 2003.

Chen, J. M., Menges, C. H., and Leblanc, S. G.: Global derivation of the vegetation clumping index from multi-angular satellite data, Remote Sens. Environ., 97, 447-457, 2005.

Chen, J. M., Mo, G., Pisek, J., Deng, F., Ishozawa, M., and Chan, D.: Effects of foliage clumping on global terrestrial gross primary productivity, Global Biogeochem. Cy., 26, GB1019, doi:10.1029/2010GB003996, 2012.

Ciais, P., Bousquet, P., Freibauer, A., and Naegler, T.: Horizontal displacement of carbon associated with agriculture and its impacts on atmospheric $\mathrm{CO}_{2}$, Global Biogeochem. Cy., 21, 1-12, doi:10.1029/2006GB002741, 2007.

Corbin, K. D., Denning, A. S., Lokupitiya, E. Y., Schuh, A. E., Miles, N. L., Davis, K. J., Richardson, S., and Baker, I. T.: Assessing the impact of crops on regional $\mathrm{CO}_{2}$ fluxes and atmospheric concentrations, Tellus, 62, 521-532, doi:10.1111/j.16000889.2010.00485.x, 2010.

Crevoisier, C., Sweeney, C., Gloor, M., Sarmientob, J. L., and Tans, P. P.: Regional US carbon sinks from three-dimensional atmospheric $\mathrm{CO}_{2}$ sampling, P. Natl. Acad. Sci. USA, 107, 1834818353, doi:10.1073/pnas.0900062107, 2010.

DeFries, R. and Townshend, J. R.: NDVI-derived land cover classifications at a global scale, Int. J. Remote Sens., 15, (May 2012), 37-41, 1994.

Deng, F. and Chen, J. M.: Recent global $\mathrm{CO}_{2}$ flux inferred from atmospheric $\mathrm{CO}_{2}$ observations and its regional analyses, Biogeosciences, 8, 3263-3281, doi:10.5194/bg-8-3263-2011, 2011.

Deng, F., Chen, J. M., and Plummer, S.: Algorithm for global leaf area index retrieval using satellite imagery, IEEE T. Geosci. Remote, 44, 2219-2229, 2006.

Deng, F., Chen, J. M., Ishizawa, M., Yuen, C.-W., Mo, G., Higuchi, K., Chan, D., Chen, B., and Maksyutov, S.: Global monthly $\mathrm{CO}_{2}$ flux inversion with a focus over North America, Tellus, 59, 179190, doi:10.1111/j.1600-0889.2006.00235.x, 2007.

Deng, F., Chen, J. M., Pan, Y., Peters, W., Birdsey, R., McCullough, $\mathrm{K}$., and Xiao, J.: The use of forest stand age information in an atmospheric $\mathrm{CO}_{2}$ inversion applied to North America, Biogeosciences, 10, 5335-5348, doi:10.5194/bg-10-5335-2013, 2013.

Denning, A. S., Fung, I. Y., and Randall, D.: Latitudinal gradient of atmospheric $\mathrm{CO}_{2}$ due to seasonal exchange with land biota, Nature, 76, 240-243, doi:10.1038/376240a0, 1995.

Enting, I. G.: Inverse Problems, Carbon, 392 pp., Cambridge University Press, Atmospheric Constituent Transport, doi:10.1017/CBO9780511535741, 2002.

Enting, I. and Trudinger, C.: A synthesis inversion of the concentration and $\delta ;{ }^{13} \mathrm{C}$ of atmospheric $\mathrm{CO}_{2}$, Tellus, B47, 35-52, doi:10.1034/j.1600-0889.47.issue1.5.x, 1995. 
Fan, S.: A Large Terrestrial Carbon Sink in North America Implied by Atmospheric and Oceanic Carbon Dioxide Data and Models, Science, 282, 442-446, doi:10.1126/science.282.5388.442, 1998.

Gourdji, S. M., Mueller, K. L., Yadav, V., Huntzinger, D. N., Andrews, A. E., Trudeau, M., Petron, G., Nehrkorn, T., Eluszkiewicz, J., Henderson, J., Wen, D., Lin, J., Fischer, M., Sweeney, C., and Michalak, A. M.: North American $\mathrm{CO}_{2}$ exchange: inter-comparison of modeled estimates with results from a fine-scale atmospheric inversion, Biogeosciences, 9, 457-475, doi:10.5194/bg-9-457-2012, 2012.

Gurney, K. R., Law, R. M., Denning, A. S., Rayner, P. J., Baker, D., Bousquet, P., Bruhwiler, L., Chen, Y. H., Ciais, P., Fan, S., Fung, I. Y., Gloor, M., Heimann, M., Higuchi, K., John, J., Maki, T., Maksyutov, S., Masarie, K., Peylin, P., Prather, M., Pak, B. C., Randerson, J., Sarmiento, J., Taguchi, S., Takahashi, T., and Yuen, C. W.: Towards robust regional estimates of $\mathrm{CO}_{2}$ sources and sinks using atmospheric transport models, Nature, 415, 62630, doi:10.1038/415626a, 2002.

Gurney, K. R., Law, R. M., Denning, A. S., Rayner, P. J., Baker, D., Bousquet, P., Bruhwiler, L., Chen, Y. H., Ciais, P., Fan, S., Fung, I. Y., Gloor, M., Heimann, M., Higuchi, K., John, J., Kowalczyk, E., Maki, T., Maksyutov, S., Peylin, P., Prather, M., Pak, B. C., Sarmiento, J., Taguchi, S., Takahashi, T., and Yuen, C. $\mathrm{W}$.: TransCom $3 \mathrm{CO}_{2}$ inversion intercomparison: 1 . Annual mean control results and sensitivity to transport and prior flux information, Tellus, 55, 555-579, 2003.

Gurney, K. R., Law, R. M., Denning, A. S., Rayner, P. J., Pak, B. C., Baker, D., Bousquet, P., Bruhwiler, L., Chen, Y.-H., Ciais, P., Fung, I. Y., Heiman, M., John, J., Maki, T., Maksyutov, S., Peylin, P., Prather, M., and Taguchi, S.: Transcom 3 inversion intercomparison: Model mean results for the estimation of seasonal carbon sources and sinks, Global Biogeochem. Cy., 18, GB1010, doi:10.1029/2003GB002111, 2004.

Hayes, D. J., Turner, D. P., Stinson, G., McGuire, a. D., Wei, Y., West, T. O., Heath, L. S., de Jong, B., McConkey, B. G., Birdsey, R. A., Kurz, W. A., Jacobson, A. R., Huntzinger, D. N., Pan, Y., Post, W. M., and Cook, R. B: Reconciling estimates of the contemporary North American carbon balance among terrestrial biosphere models, atmospheric inversions, and a new approach for estimating net ecosystem exchange from inventory-based data, Glob. Change Biol., 18, 1282-1299, doi:10.1111/j.13652486.2011.02627.x, 2012.

He, L., Chen, J. M., Pisek, J., Schaaf, C. B., and Strahler, A. H.: Global clumping index map derived from the MODIS BRDF product, Remote Sens. Environ., 119, 118-130, 2012.

Hicke, J. A.: Spatiotemporal patterns of cropland area and net primary production in the central United States estimated from USDA agricultural information, Geophys. Res. Lett., 31, 1-5, doi:10.1029/2004GL020927, 2004.

Hicke, J. A. and Lobell, D.: Cropland area and net primary production computed from 30 years of USDA agricultural harvest data, Earth Interact., 8, 1-20, 2004.

Higuchi, K., Shashkov, A., Chan, D., Saigusa, N., Murayama, S., Yamamoto, S., Kondo, H., Chen, J. M., Liu, J., and Chen, B.: Simulations of seasonal and inter-annual variability of gross primary productivity at Takayama with BEPS ecosystem model, Agr. Forest Meteorol., 134, 143-150, doi:10.1016/j.agrformet.2005.08.018, 2005.
Huntzinger, D. N., Post, W. M., Wei, Y., Michalak, a. M., West, T. O., Jacobson, a. R., Baker, I. T., Jacobson, A. R., Baker, I. T., Chen, J. M., Davis, K. J., Hayes, D. J., Hoffman, F. M., Jain, A. K., Liu, S., McGuire, A. D., Neilson, R. P., Potter, C., Poulter, B., Price, D., Raczka, B. M., Tian, H. Q., Thornton, P., Tomelleri, E., Viovy, N., Xiao, J., Yuan, W., Zeng, N., Zhao, M., and Cook, R.: North American Carbon Program (NACP) regional interim synthesis: Terrestrial biospheric model intercomparison, Ecol. Model., 232, 144-157, doi:10.1016/j.ecolmodel.2012.02.004, 2012.

Ju, W., Chen, J. M., Black, T. A., Barr, A. G., Liu, J., and Chen, B.: Modelling multi-year coupled carbon and water fluxes in a boreal aspen forest, Agr. Forest Meteorol., 140, 136-151, doi:10.1016/j.agrformet.2006.08.008, 2006.

Kalnay, E., Kanamitsu, M., Kistler, R., Collins, W., Deaven, D., Gandin, L., Iredell, M., Saha, S., White, G., Woollen, J., Zhu, Y., Leetmaa, A., Reynolds, B., Chelliah, M., Ebisuzaki, W., Higgins, W., Janowiak, J., Mo, K. C., Ropelewski, C., Wang, J., Jenne, R., and Joseph, D.: The NCEP/NCAR 40-year reanalysis project, B. Am. Meteorol. Soc., 77, 437-471, 1996.

Kurz, W. A. and Apps, M. J.: A 70-year retrospective analysis of carbon fluxes in the Canadian forest sector, Ecol. Appl., 9, 526547, 1999.

Krol, M., Houweling, S., Bregman, B., van den Broek, M., Segers, A., van Velthoven, P., Peters, W., Dentener, F., and Bergamaschi, P.: The two-way nested global chemistry-transport zoom model TM5: algorithm and applications, Atmos. Chem. Phys., 5, 417432, doi:10.5194/acp-5-417-2005, 2005.

Lauvaux, T., Schuh, A. E., Uliasz, M., Richardson, S., Miles, N., Andrews, A. E., Sweeney, C., Diaz, L. I., Martins, D., Shepson, P. B., and Davis, K. J.: Constraining the $\mathrm{CO}_{2}$ budget of the corn belt: exploring uncertainties from the assumptions in a mesoscale inverse system, Atmos. Chem. Phys., 12, 337-354, doi:10.5194/acp-12-337-2012, 2012.

Le Quéré, C., Raupach, M. R., Canadell, J. G., Marland, G., Bopp, L., Ciais, P., Conway, T. J., Doney, S. C., Feely, R. A., Foster, P. N., Friedlingstein, P., Gurney, K., Houghton, R. A., House, J. I., Huntingford, C., Levy, P. E., Lomas, M. R., Majkut, J., Metzl, N., Ometto, J. P., Peters, G. P., Prentice, I. C., Randerson, J. T., Running, S. W., Sarmiento, J. L., Schuster, U., Sitch, S., Takahashi, T., Viovy, N., van der Werf, G. R. and Woodward, F. I.: Trends in the sources and sinks of carbon dioxide, Nat. Geosci., 2, 831-836, doi:10.1038/ngeo689, 2009.

Le Quéré, C., Andres, R. J., Boden, T., Conway, T., Houghton, R. A., House, J. I., Marland, G., Peters, G. P., van der Werf, G. R., Ahlström, A., Andrew, R. M., Bopp, L., Canadell, J. G., Ciais, P., Doney, S. C., Enright, C., Friedlingstein, P., Huntingford, C., Jain, A. K., Jourdain, C., Kato, E., Keeling, R. F., Klein Goldewijk, K., Levis, S., Levy, P., Lomas, M., Poulter, B., Raupach, M. R., Schwinger, J., Sitch, S., Stocker, B. D., Viovy, N., Zaehle, S., and Zeng, N.: The global carbon budget 1959-2011, Earth Syst. Sci. Data, 5, 165-185, doi:10.5194/essd-5-165-2013, 2013.

Liu, J., Chen, J. M., Cihlar, J., and Chen, W.: Net primary productivity distribution in the BOREAS region from a process model using satellite and surface data, J. Geophys. Res., 104, 27735 27754, 1999.

Liu, J., Chen, J. M., Cihlar, J., and Chen, W.: Net primary productivity mapped for Canada at $1 \mathrm{~km}$ resolution, Glob. Ecol. Biogeogr., 11, 115-129, 2002. 
Madec, G., Delecluse, P., Imbard, M., and Levy, C.: OPA 8.1 Ocean General Circulation Model reference manual, Notes du pôle de modélisation Institut Pierre Simon Laplace IPSL France, 11, 91 pp., 1998.

Marland, G., Hamal, K., and Jonas, M.: How Uncertain Are Estimates of $\mathrm{CO}_{2}$ Emissions?, J. Ind. Ecol., 13, 4-7, doi:10.1111/j.1530-9290.2009.00108.x, 2009.

Masarie, K. and Tans, P. P.: Extension and integration of atmospheric carbon dioxide data into a globally consistent measurement record, J. Geophys. Res., 100, 11593-11, 1995.

Matsushita, B. and Tamura, M.: Integrating remotely sensed data with an ecosystem model to estimate net primary productivity in East Asia, Remote Sens. Environ., 81, 58-66, 2002.

Olivier, J. and Aardenne, J. V.: Recent trends in global greenhouse gas emissions: regional trends 1970-2000 and spatial distribution of key sources in 2000, Environ. Sci., 2, 81-99, 2005.

Pacala, S., Hurtt, G., Baker, D., and Peylin, P.: Consistent landand atmosphere-based US carbon sink estimates, Science, 292, 2316-2320, 2001.

Pan, Y., Birdsey, R. A., Fang, J., Houghton, R. a., Kauppi, P. E., Kurz, W. A., Phillips, O. L., Shvidenko, A., Lewis, S. L., Canadell, J. G., Ciais, P., J ackson, R. B., Pacala, S., McGuire, A. D., Piao, S., Rautiainen, A., and Sitch, S.: A large and persistent carbon sink in the World's forests, Science, 333, 988-993, 2011a.

Pan, Y., Chen, J. M., Birdsey, R., McCullough, K., He, L., and Deng, F.: Age structure and disturbance legacy of North American forests, Biogeosciences, 8, 715-732, doi:10.5194/bg-8-7152011, 2011b.

Peters, W., Miller, J. B., Whitaker, J., Denning, A. S., Hirsch, A., Krol, M. C., Zupanski, D., Bruhwiler, L., and Tans, P. P.: An ensemble data assimilation system to estimate $\mathrm{CO}_{2}$ surface fluxes from atmospheric trace gas observations, J. Geophys. Res., 110, D24304, doi:10.1029/2005JD006157, 2005.

Peters, W., Jacobson, A. R., Sweeney, C., Andrews, A. E., Conway, T. J., Masarie, K., Miller, J. B., Bruhwiler, L. M. P., Petron, G., Hirsch, A. I., Worthy, D. E. J., van der Werf, G. R., Randerson, J. T., Wennberg, P. O., Krol, M. C., and Tans, P. P.: An atmospheric perspective on North American carbon dioxide exchange: CarbonTracker, P. Natl. Acad. Sci. USA, 104, 1892518930, doi:10.1073/pnas.0708986104, 2007.

Peylin, P., Law, R. M., Gurney, K. R., Chevallier, F., Jacobson, A. R., Maki, T., Niwa, Y., Patra, P. K., Peters, W., Rayner, P. J., Rödenbeck, C., van der Laan-Luijkx, I. T., and Zhang, X.: Global atmospheric carbon budget: results from an ensemble of atmospheric $\mathrm{CO}_{2}$ inversions, Biogeosciences, 10, 6699-6720, doi:10.5194/bg-10-6699-2013, 2013.

Prince, S. D., Haskett, J., Steininger, M., Strand, H., and Wright, R. Net primary production of US Midwest croplands from agricultural harvest yield data, Ecol. Appl., 11, 1194-1205, 2001.

Randerson, J. T., Thompson, V., Conway, T. J., Fung, I. Y., and Field, B. The contribution of terrestrial sources and sinks to trends in the seasonal cycle of atmospheric carbon dioxide, Global Biogeochem. Cy., 11, 535-560, 1997.

Randerson, J. T., Van Der Werf, G. R., Giglio, L., Collatz, G. J., and Kasibhatla, P. S.: Global Fire Emissions Database, Version 2 (GFEDv2.1), Data set, Oak Ridge National Laboratory Distributed Active Archive Center Oak Ridge Tennessee USA, 2007.
Running, S. W. and Coughlan, J. C.: A general model of forest ecosystem processes for regional applications I, Hydrologic balance, canopy gas exchange and primary production processes, Ecol. Model., 42, 125-154, 1988.

Rödenbeck, C., Houweling, S., Gloor, M., and Heimann, M.: $\mathrm{CO}_{2}$ flux history 1982-2001 inferred from atmospheric data using a global inversion of atmospheric transport, Atmos. Chem. Phys., 3, 1919-1964, doi:10.5194/acp-3-1919-2003, 2003.

Schuh, A. E., Denning, A. S., Corbin, K. D., Baker, I. T., Uliasz, M., Parazoo, N., Andrews, A. E., and Worthy, D. E. J.: A regional high-resolution carbon flux inversion of North America for 2004, Biogeosciences, 7, 1625-1644, doi:10.5194/bg-71625-2010, 2010.

Schuh, A. E., Lauvaux, T., West, T. O., Denning, S., Davis, K., Miles, N., Richardson, S., Uliasz, M., Lokupitiya, E., Cooley, S., Andrews, A., and Ogle, S. Evaluating atmospheric $\mathrm{CO}_{2}$ inversions at multiple scales over a highly inventoried agricultural landscape, Glob. Change Biol., 19, 1424-1439, doi:10.1111/gcb.12141, 2013.

Sun, R., Chen, J., Zhu, Q., Zhou, Y., and Liu, J.: Spatial distribution of net primary productivity and evapotranspiration in Changbaishan Natural Reserve, China, using Landsat ETM+ data, Can. J. Remote Sens., 30, 731-742, 2004.

Tarantola, A.: Inverse Problem Theory, published by SIAM: Society for Industrial and Applied Mathematics, Physica B, 130, 77-78, doi:10.1137/1.9780898717921, 2005.

Turner, D. P, Jacobson, A. R., Ritts, W. D., Wang W. L., and Nemani, R.: A Large Proportion of North American Net Ecosystem Production is Offset by Emissions from Harvested Products, River/Stream Evasion, and Biomass Burning, Glob. Change Biol., Glob. Change Biolo., 19, C3528, doi:10.1111/gcb.12313, 2013.

Webb, R. S., Rosenzweig, C. E., and Levine, E. R.: A global data set of soil particle size properties, NASA Tech. Memo., TM-4286, 40 pp., 1991.

West, T. O., Brandt, C. C., Wilson, B. S., Hellwinckel, C. M., Tyler, D. D., Marland, G., De La Torre Ugarte, D. G., Larson, J. A., and Nelson, R. G.: Estimating Regional Changes in Soil Carbon with High Spatial Resolution, Soil Sci. Soc. Am. J., 72, 285. doi:10.2136/sssaj2007.0113, 2008.

West, T. O., Marland, G., Singh, N., Bhaduri, B. L., and Roddy, A. B.: The human carbon budget: an estimate of the spatial distribution of metabolic carbon consumption and release in the United States, Biogeochemistry, 94, 29-41, doi:10.1007/s10533009-9306-z, 2009.

West, T. O., Brandt, C. C., Baskaran, L. M., Hellwinckel, C. M., Mueller, R., Bernacchi, C. J., Bandaru, V., Yang, B., Wilson, B. S., Marland, G., Nelson, R. G., De la Torre Ugarte, D. G., and Post, W. M.: Cropland carbon fluxes in the United States: increasing geospatial resolution of inventory-based carbon accounting, Ecol. Appl., 20, 1074-86, 2010.

West, T. O., Bandaru, V., Brandt, C. C., Schuh, A. E., and Ogle, S. M.: Regional uptake and release of crop carbon in the United States, Biogeosciences, 8, 2037-2046, doi:10.5194/bg-8-20372011, 2011.

Williams, C. A., Collatz, G. J., Masek, J., and Goward, S. N.: Carbon consequences of forest disturbance and recovery across the conterminous United States, Global Biogeochem. Cy., 26, GB1005, doi:10.1029/2010GB003947, 2012. 
Yuen, C. W., Higuchi, K., Baker, D., Bousquet, P., Bruhwiler, L., Chen, Y. H., Ciais, P., Denning, A. S., Fan, S., Fung, I., Gloor, M., Gurney, K. R., Heimann, M., John, J., Law, R. M., Maki, T., Maksyutov, S., Pak, B., Peylin, P., Prather, M., Rayner, P., Sarmiento, J., Taguchi, S. and Takahashi, T.: : Impact of Fraserdale $\mathrm{CO}_{2}$ observations on annual flux inversion of the North American boreal region, Tellus, B75, 203-209, 2005.

van der Werf, G. R., Randerson, J. T., Giglio, L., Collatz, G. J., Kasibhatla, P. S., and Arellano Jr., A. F.: Interannual variability of global biomass burning emissions from 1997 to 2004, Atmos. Chem. Phys. Discuss., 6, 3175-3226, doi:10.5194/acpd-6-31752006, 2006.

van der Werf, G. R., Randerson, J. T., Giglio, L., Collatz, G. J., Mu, M., Kasibhatla, P. S., Morton, D. C., DeFries, R. S., Jin, Y., and van Leeuwen, T. T.: Global fire emissions and the contribution of deforestation, savanna, forest, agricultural, and peat fires (19972009), Atmos. Chem. Phys., 10, 11707-11735, doi:10.5194/acp10-11707-2010, 2010.
Verma S. B., Dobermann A., Cassman K. G., Walters D. T., Knops J. M., Arkebauer T. J., Suyker A. E., Burba G. G., Amos B., Yang H., Ginting D., Hubbard K. G., Gitelson A. A., and Walter-Shea E. A.: Annual carbon dioxide exchange in irrigated and rainfed maize-based agroecosystems, Agr. Forest Meteorol., 131, 77-96, 2005.

Zhang, F. M., Chen, J. M., Birdsey, R. A., Pan, Y., Shen, S., Ju, W. J., and He, L.: Attributing carbon changes in conterminous US forests to disturbance and non-disturbance factors from 1901 to 2010, J. Geophys. Res.-Biogeo., 117, G02021, doi:10.1029/2011JG001930, 2012. 